\title{
Factors Impacting $\sigma$ - and $\pi$-Hole Regions as Revealed by the Electrostatic Potential and Its Source Function Reconstruction: The Case of 4,4'-Bipyridine Derivatives
}

\author{
Carlo Gatti ${ }^{1,2}, *(\mathbb{D})$, Alessandro Dessì ${ }^{3}\left(\mathbb{0}\right.$, Roberto Dallocchio ${ }^{3}\left(\mathbb{D}\right.$, Victor Mamane ${ }^{4, *(\mathbb{D})}$, \\ Sergio Cossu ${ }^{5}$, Robin Weiss ${ }^{4}$, Patrick Pale ${ }^{4}\left(\mathbb{D}\right.$, Emmanuel Aubert ${ }^{6}$ and Paola Peluso ${ }^{3, *(D)}$ \\ 1 CNR-SCITEC, Istituto di Scienze e Tecnologie Chimiche "Giulio Natta”, sezione di via Golgi, \\ via C. Golgi 19, 20133 Milano, Italy \\ 2 Istituto Lombardo, Accademia di Scienze e Lettere, via Brera 28, 20100 Milano, Italy \\ 3 Institute of Biomolecular Chemistry ICB, CNR, Secondary branch of Sassari, Traversa La Crucca 3, \\ Regione Baldinca, Li Punti, 07100 Sassari, Italy; alessandro.dessi@cnr.it (A.D.); \\ roberto.dallocchio@cnr.it (R.D.) \\ 4 Strasbourg Institute of Chemistry, UMR CNRS 7177, Team LASYROC, 1 rue Blaise Pascal, \\ University of Strasbourg, 67008 Strasbourg, France; robin.weiss@unistra.fr (R.W.); ppale@unistra.fr (P.P.) \\ 5 Department of Molecular Science and Nanosystems DSMN, Venice Ca' Foscari University, Via Torino 155, \\ 30172 Mestre Venezia, Italy; cossu@unive.it \\ 6 Crystallography, Magnetic Resonance and Modelling (CRM2), UMR CNRS 7036, University of Lorraine, \\ Bd des Aiguillettes, 54506 Vandoeuvre-les-Nancy, France; emmanuel.aubert@univ-lorraine.fr \\ * Correspondence: c.gatti@scitec.cnr.it (C.G.); vmamane@unistra.fr (V.M.); paola.peluso@cnr.it (P.P.); \\ Tel.: +39-02-50314277 (C.G.); +33-3-68851612 (V.M.); +39-079-2841218 (P.P.)
}

Academic Editor: Ricardo Mosquera

Received: 7 September 2020; Accepted: 23 September 2020; Published: 25 September 2020

\begin{abstract}
Positive electrostatic potential $(V)$ values are often associated with $\sigma$ - and $\pi$-holes, regions of lower electron density which can interact with electron-rich sites to form noncovalent interactions. Factors impacting $\sigma$-and $\pi$-holes may thus be monitored in terms of the shape and values of the resulting $V$. Further precious insights into such factors are obtained through a rigorous decomposition of the $V$ values in atomic or atomic group contributions, a task here achieved by extending the Bader-Gatti source function (SF) for the electron density to $V$. In this article, this general methodology is applied to a series of 4,4'-bipyridine derivatives containing atoms from Groups VI (S, Se) and VII $(\mathrm{Cl}, \mathrm{Br})$, and the pentafluorophenyl group acting as a $\pi$-hole. As these molecules are characterized by a certain degree of conformational freedom due to the possibility of rotation around the two C-Ch bonds, from two to four conformational motifs could be identified for each structure through conformational search. On this basis, the impact of chemical and conformational features on $\sigma$ - and $\pi$-hole regions could be systematically evaluated by computing the $V$ values on electron density isosurfaces $\left(V_{\mathrm{S}}\right)$ and by comparing and dissecting in atomic/atomic group contributions the $V_{\mathrm{S}}$ maxima $\left(V_{\mathrm{S}, \max }\right)$ values calculated for different molecular patterns. The results of this study confirm that both chemical and conformational features may seriously impact $\sigma$ - and $\pi$-hole regions and provide a clear analysis and a rationale of why and how this influence is realized. Hence, the proposed methodology might offer precious clues for designing changes in the $\sigma$ - and $\pi$-hole regions, aimed at affecting their potential involvement in noncovalent interactions in a desired way.
\end{abstract}

Keywords: atomic group contributions; bipyridines; chalcogen bond; electrostatic potential; halogen bond; $\sigma$-hole; $\pi$-hole; source function 


\section{Introduction}

The electrostatic potential computed on a molecular electron density isosurface $\left(V_{\mathrm{S}}\right)$ is beneficially used to assess electronic properties and interaction capability of specific atoms and sites [1,2]. $V(\mathbf{r})$ is a real physical property which represents the electrostatic potential in a point $\mathbf{r}[3] . V(\mathbf{r})$ is generated by each nucleus in a system and by the system's electron distribution, and is given by Equation (1):

$$
V(\mathbf{r})=\sum_{\mathrm{A}} \frac{\mathrm{Z}_{\mathrm{A}}}{\mathbf{R}_{\mathrm{A}}-\mathbf{r}}-\int \frac{\rho(\mathbf{r}) \mathrm{d} \mathbf{r}^{\prime}}{\left|\mathbf{r}^{\prime}-\mathbf{r}\right|}
$$

where $Z_{A}$ is the charge on nucleus $A$ located at $\mathbf{R}_{A}$, and $\rho(\mathbf{r})$ is the electron density distribution. The sign of $V(\mathbf{r})$ is positive or negative if the effect of the nuclei (first positive term) or that of electrons (second negative term) is dominant, respectively. Significantly, the analysis of $V_{\mathrm{S}}$ values disclosed that $V$ around bound atoms of Groups III-VIII is anisotropic due to the presence of regions of electron charge density depletion ( $\sigma$-holes) which are able to interact with electron-rich regions [4-7]. Several studies have proven that computing $V$ associated with a $\sigma$-hole in its unperturbed state can furnish a useful estimation of the strength of potential noncovalent interactions involving the electropositive region [2,5]. Among noncovalent interactions related to the $\sigma$-hole concept, the well-known halogen [8] and chalcogen [9] bonds ( $\mathrm{XB}$ and $\mathrm{ChB}$, respectively) have been studied and applied in several fields for decades [10-13]. Because $V$ in a region depends on the contributions of the whole molecule [14,15], seminal studies have focused on the structural factors which affect local $V$ by using simple compounds as test probes $[14,16-18]$. On the other hand, understanding the factors which impact $\sigma$-hole in complex systems is important in designing new molecules for applicative purposes [19-22]. Many XB and $\mathrm{ChB}$ donors reported so far are based on the use of electron-attracting heterocyclic systems which induce polarization in bound atoms of Groups VI and VII, enhancing their electrophilic character $[12,23,24]$. Fluorination also increases $\sigma$ - and $\pi$-hole depth [25], $\pi$-holes being electron deficient regions often observed on polarized double bond and $\pi$-acidic aromatics, and able to interact with nucleophiles [26,27].

In the last few years, our groups have demonstrated that the $4,4^{\prime}$-bipyridyl moiety provides polarization of bound $\mathrm{X}$ atoms. Halogenated $4,4^{\prime}$-bipyridines have been found to act as XB donors in solid-state [28,29] and in solution [30,31]. Recently, the series of 5,5'-dibromo-2,2'-dichloro3-chalcogeno-4,4'-bipyridines 1-6 (Figure 1) were designed and prepared as multi-site $\sigma$-hole donors [32,33], derivatives 3 and $\mathbf{6}$ also containing a $\pi$-hole centered on a pentafluorophenyl ring. In particular, compounds 2, 3 and 6 were shown to function as $\sigma$ - and $\pi$-hole donors in chiral recognition [32], ${ }^{19}$ F-NMR titration and catalysis experiments [33]. From the structural point of view, compounds 1-6 bear different combinations of $\mathrm{Ch}$ atom ( $\mathrm{S}$ and $\mathrm{Se}$ ) and a distinctive substituent on $\mathrm{Ch}\left(\mathrm{Me}, \mathrm{Ph}, \mathrm{C}_{6} \mathrm{~F}_{5}\right)$ on a tetrahalogenated $4,4^{\prime}$-bipyridine scaffold $(\mathrm{X}=\mathrm{Cl}, \mathrm{Br})$. Moreover, the 3-chalcogeno-4,4'-bipyridyl motif is characterized by a degree of conformational freedom due to the possibility of rotation around the two $\mathrm{C}-\mathrm{Ch}$ bonds (Figure 1). On the contrary, rotation around the 4, $4^{\prime}$-axis is restricted due to the effect of sterically hindered 3,5,5'-substituents (atropisomerism), and consequently the two pyridyl rings ( $p y r$ and $p y r^{\prime}$ ) are not coplanar and almost orthogonal. In general, motifs used as $\mathrm{ChB}$ donors for applicative purposes are characterized by low conformational flexibility to enhance the directionality feature of the noncovalent interaction [12,34]. On the other hand, to date systematic studies and observations focused on the impact of molecular conformational features on $\sigma$ - and $\pi$-holes incorporated in a structure are scarcely reported [35-38]. 


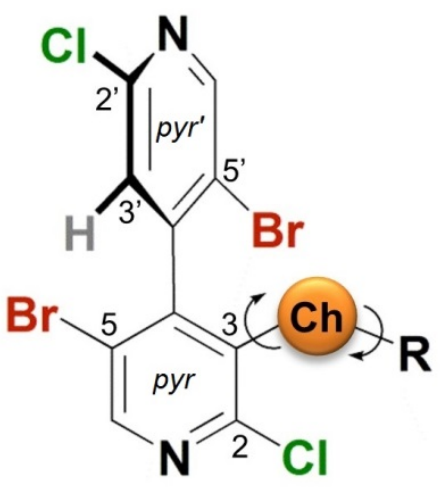

Substitution pattern

1: $\mathrm{Ch}=\mathrm{S}, \mathrm{R}=\mathrm{Me}$

2: $\mathrm{Ch}=\mathrm{S}, \mathrm{R}=\mathrm{Ph}$

3: $\mathrm{Ch}=\mathrm{S}, \mathrm{R}=\mathrm{C}_{6} \mathrm{~F}_{5}$

4: $\mathrm{Ch}=\mathrm{Se}, \mathrm{R}=\mathrm{Me}$

5: $\mathrm{Ch}=\mathrm{Se}, \mathrm{R}=\mathrm{Ph}$

6: $\mathrm{Ch}=\mathrm{Se}, \mathrm{R}=\mathrm{C}_{6} \mathrm{~F}_{5}$

Figure 1. Structure of (M)-5,5'-dibromo-2,2'-dichloro-3-chalcogeno-4,4'-bipyridines 1-6.

In this article, using compounds 1-6 as test probes to explore a multi-site system, we describe a study aimed at evaluating how the impact of chemical and conformational features on the environment around $\sigma$ - and $\pi$-holes affects the $V_{\mathrm{S}}$ maxima $\left(V_{\mathrm{S}, \max }\right)$ related to these regions. Our study is composed of two steps in sequence (Section 2). In the first one (Sections 2.1 and 2.2), we search the stable conformers of each compound, we calculate their corresponding $V_{\mathrm{S}, \max }$ values and analyze the factors impacting $\sigma$ - and $\pi$-holes in terms of the shape and values of the resulting electrostatic potentials. Then (Sections 2.3 and 2.4), a rigorous decomposition of the $V_{\mathrm{S} \text {, max }}$ values in atomic or atomic group contributions is afforded, by extending the Bader-Gatti source function (SF) for the electron density [32,39-41] to $V$ (which is analogous to adopt a suitable atomic partition for $\rho$ (r) in Equation (1)). Factors impacting $\sigma$ - and $\pi$-holes may be so dissected in separate contributions from chemically meaningful moieties of the molecule that regardless of their being close or far from the holes, can either (over/partly) contribute to or oppose the observed $V_{\mathrm{S} \text {, max }}$ values. Such a dissection provides unprecedented insights into the factors leading to $V_{\mathrm{S} \text {,max }}$ value changes and trends. In fact, as an example, while it is well acknowledged that $\sigma$-holes originate from the cylindrical symmetry of the $\sigma$-bond and the more or less asymmetric electron sharing along its axis, nothing is quantitatively known about the synergic or antagonist roles played by the various moieties of a molecule in producing such holes. Section 3 reports technical details about our adopted methodology and the performed computations, while Section 4 concludes.

It is expected that our two-step methodology may serve as a valid tool for designing changes in the $\sigma$ - and $\pi$-hole regions of families of molecular compounds, aimed at affecting their (potential) involvement in noncovalent interactions in a desired manner.

\section{Results and Discussion}

In a previous study, we demonstrated that different conformers of compounds 3-6 exist in ethanol [33]. On this basis, with the aim of identifying low energy conformers for compounds 1-6 in vacuum, a conformational search procedure was carried out for each compound (see Supplementary Information, Table S1 for energies, geometric parameters, and Boltzmann distributions). Conformational motifs A1 and A2 were found for compounds 1, 4, and 5, and A1, B1, A2, and B2 for compounds 2, 3, and 6 (Figure 2 and Supplementary Information, Figure S1). 
(a)

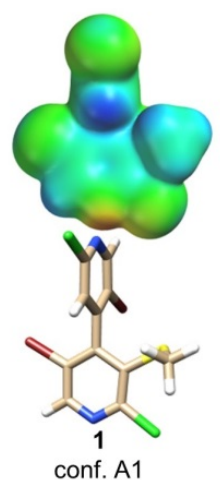

(b)

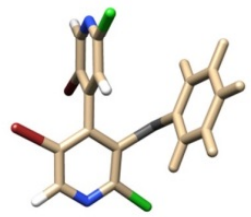

conf. A1

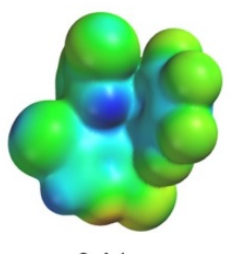

6-A1
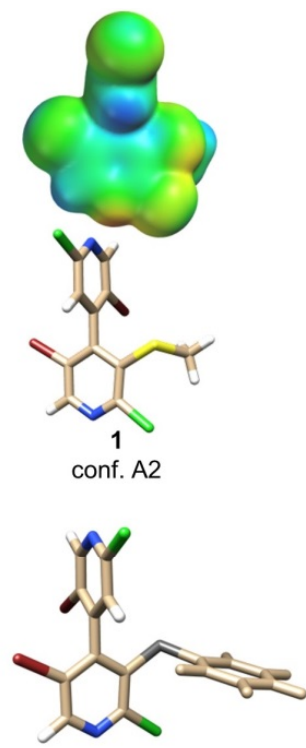

conf. B1

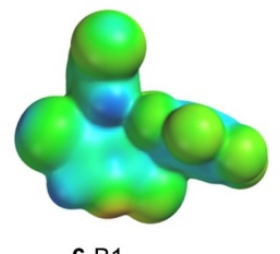

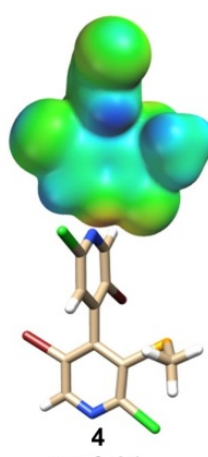

conf. A1

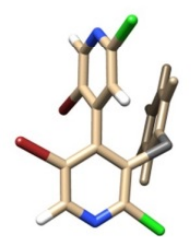

conf. A2

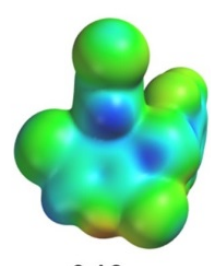

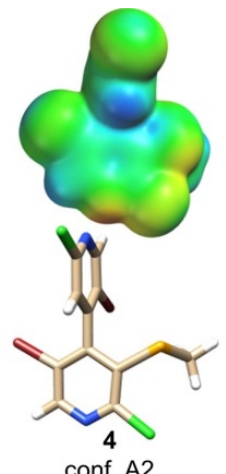

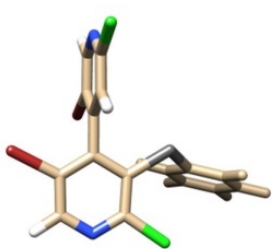

conf. B2

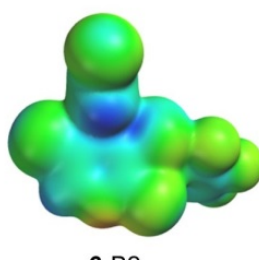

Figure 2. Conformations and related $V_{\mathrm{S}}$ representations on electron density isosurfaces (0.002 au) graphically generated by using Spartan' 10 (DFT/B3LYP/6-311G*): (a) $V_{\mathrm{S}}$ representations and tube structures of conformers A1 and A2 calculated for compound $\mathbf{1}$ and 4, (b) conformation motifs A1, B1, A2 and B2 computed for compounds 2, 3, and 6, and (c) $V_{\mathrm{S}}$ representations of conformers A1, B1, A2, and $\mathrm{B} 2$ of compound $\mathbf{6}\left(V_{\mathrm{S}}\right.$ representations for conformers of $\mathbf{2}, \mathbf{3}$, and $\mathbf{5}$ are depicted in Supplementary Information). Tube structures colors: bromine (red), chalcogen $\mathrm{S} / \mathrm{Se}$ (dark grey), chlorine (green), hydrogen (white), nitrogen (blue), selenium (orange), sulfur (yellow). For the $V_{\mathrm{S}}$ representations, colors towards red depict negative $V_{\mathrm{S}}$, while colors towards blue depict positive $V_{\mathrm{S}}$, and colors in between (orange, yellow, green) depict intermediate values.

They originate from the relative orientation of the 3 substituents, the methyl group (for 1 and 4 ), the phenyl (for $\mathbf{2}$ and 5), and the pentafluorophenyl (for $\mathbf{3}$ and 6) rings. These substituents can be in front (conformation A) of the $2^{\prime}$-chloro-5'-bromo-4'-pyridyl ring $\left(p y r^{\prime}\right)$ or away from it (conformation B) due to rotation around the bond $\mathrm{C} 3-\mathrm{Ch}$. For each of the two conformations $\mathrm{A}$ and $\mathrm{B}$, two additional conformers are generated by the relative position of the 3 substituents, which can be close to the $3^{\prime}$-hydrogen (conformations A1 and B1) or to the 5'-bromine atom (conformations A2 and B2) of the pyr' ring. It is worth noting that XBs and a $\pi$-hole bond were observed for conformer 6-B2 [33] by X-ray diffraction analysis. As depicted in Supplementary Information (Figure S2), during this study a Se $\cdots \mathrm{N}$ contact (ChB) was also detected in the crystal packing of conformer 5-B2.

\subsection{Calculation of $V_{S, \max }$ Values}

Using the 18 conformers of compounds 1-6 as test probes, we computed $V_{\mathrm{S}, \max }$ values for 2-Cl, $2^{\prime}-\mathrm{Cl}, 5-\mathrm{Br}, 5^{\prime}-\mathrm{Br}, 3-\mathrm{S}$ (compounds 1-3) and 3-Se (compounds 4-6) $\sigma$-holes, and phenyl $\pi$-holes (compounds 2, 3, 5 and 6) (Table 1). Recently, for compounds containing Se and X atoms, Murray and co-workers demonstrated the need for polarization functions when computing $V$ [17]. 
Table 1. $V_{\mathrm{S}, \max }(\mathrm{au})$ on halogen $(\mathrm{Cl}, \mathrm{Br})$, sulfur and selenium $\sigma$-holes $(0.002 \mathrm{au})$, and the pentafluorophenyl ring $\pi$-hole calculated for conformers of compounds 1-6 (B3LYP/6-311G*).

\begin{tabular}{|c|c|c|c|c|c|c|c|c|c|c|}
\hline Conf. & $\begin{array}{c}\mathrm{R} \\
(3-\mathrm{Ch} \underline{\mathrm{R}})\end{array}$ & $\mathrm{Ch}$ & $2^{\prime}-\mathrm{Cl}$ & $2-\mathrm{Cl}$ & $5^{\prime}-\mathrm{Br}$ & 5-Br & $\begin{array}{c}\mathrm{Ch} \\
\left(\mathrm{C}_{\text {pyridyl }}-\mathrm{Ch}\right)\end{array}$ & $\begin{array}{c}\mathrm{Ch} \\
\left(\mathrm{C}_{\mathrm{R}}-\mathrm{Ch}\right)\end{array}$ & $\begin{array}{c}\pi \text {-Hole } \\
\text { External }^{1}\end{array}$ & $\begin{array}{c}\pi \text {-Hole } \\
\text { Internal }^{1}\end{array}$ \\
\hline$\Delta V_{\mathrm{S}, \max }{ }^{2}$ & & & 0.0046 & 0.0106 & 0.0078 & 0.0055 & 0.0326 & 0.0434 & 0.0597 & 0.0685 \\
\hline 1-A2 & & & 0.0219 & 0.0262 & 0.0493 & 0.0476 & 0.0423 & - & & \\
\hline 2-A1 & $\mathrm{Ph}$ & $S$ & 0.0224 & 0.0230 & 0.0445 & 0.0475 & 0.0285 & 0.0268 & -0.0080 & - \\
\hline 2-A2 & & & 0.0215 & 0.0231 & 0.0451 & 0.0471 & 0.0267 & 0.0340 & -0.0090 & -0.0138 \\
\hline 3-A1 & $\mathrm{C}_{6} \mathrm{~F}_{5}$ & $S$ & 0.0258 & 0.0269 & 0.0520 & 0.0492 & 0.0491 & 0.0445 & 0.0466 & 0.0538 \\
\hline 3-A2 & & & 0.0246 & 0.0271 & 0.0519 & 0.0518 & 0.0491 & 0.0501 & 0.0456 & - \\
\hline 3-B1 & & & 0.0235 & 0.0307 & 0.0486 & 0.0512 & 0.0495 & $0.0272^{3}$ & 0.0470 & 0.0444 \\
\hline 3-B2 & & & 0.0250 & 0.0326 & 0.0475 & 0.0512 & 0.0512 & 0.0553 & 0.0452 & 0.0404 \\
\hline 4-A1 & $\mathrm{Me}$ & Se & 0.0229 & 0.0253 & 0.0452 & 0.0471 & 0.0521 & 0.0260 & & \\
\hline 4-A2 & & & 0.0219 & 0.0256 & 0.0486 & 0.0470 & 0.0518 & 0.0463 & & \\
\hline 6-B1 & & & 0.0235 & 0.0294 & 0.0496 & 0.0510 & 0.0582 & $0.0319^{4}$ & 0.0455 & 0.0425 \\
\hline 6-B2 & & & 0.0258 & 0.0314 & 0.0476 & 0.0510 & 0.0593 & 0.0603 & 0.0438 & 0.0390 \\
\hline
\end{tabular}

1 External and internal $\pi$-holes are oriented far from and close to the $4,4^{\prime}$-bipyridine moiety, respectively.

${ }^{2}$ Variation range of $V_{\mathrm{S} \text {, max }}$ on the corresponding $\sigma$-hole. ${ }^{3} \mathrm{~A}$ third $\sigma$-hole on the elongation of the $\mathrm{C}_{\mathrm{ArF}}-\mathrm{S}$ was found for the conformer 3-B1 with $V_{\mathrm{S}, \max }=0.0202$ au. ${ }^{4} \mathrm{~A}$ third $\sigma$-hole on the elongation of the $\mathrm{C}_{\mathrm{ArF}}-\mathrm{Se}$ was found for the conformer 6-B1 with $V_{\mathrm{S}, \max }=0.0309 \mathrm{au}$.

A comparative analysis performed by using conformer 6-B1 as a representative case confirmed that for basis sets such as 3-21G* and larger, results and trends of $V_{\mathrm{S}}$ values associated with the holes for the B3LYP and M06-2X methods do not greatly differ (see Supplementary Information, Table S2 and Figure S3). On this basis, the calculations were performed in vacuum, at DFT level of theory, with the B3LYP functional and 6-311G* as basis set mapping the $V_{\mathrm{S}}$ on a 0.002 au isodensity surface of the unperturbed molecules [2]. This isodensity surface was used to detect properly small $\sigma$-holes. Indeed, using conformer 1-A2 as a model, the $V_{\mathrm{S}, \max }$ on the sulfur $\sigma$-holes were computed, by using different isodensity envelopes ranging from 0.001 to 0.004 au (Table 2). The surface of bonded sulfur along the $\mathrm{C}-\mathrm{S}$ bond elongations does not enclose a $\sigma$-hole when the potential is mapped on the $0.001 \mathrm{au}$ isodensity surface.

Table 2. $V_{\mathrm{S}, \max }(\mathrm{au})$ calculated on the $\mathrm{S} \sigma$-holes in conformer 1-A2 at isodensity surfaces $0.001-0.004$ au.

\begin{tabular}{ccccc}
\hline $\boldsymbol{\sigma}$-hole & $\mathbf{0 . 0 0 1}$ & $\mathbf{0 . 0 0 2}$ & $\mathbf{0 . 0 0 3}$ & $\mathbf{0 . 0 0 4}$ \\
\hline$\sigma$-hole $\left(\mathrm{C}_{\text {pyridyl }}-\mathrm{S}\right)$ & - & 0.0422 & 0.0502 & 0.0590 \\
$\sigma$-hole $\left(\mathrm{C}_{\mathrm{Me}}-\mathrm{S}\right)$ & - & - & - & 0.0578 \\
\hline
\end{tabular}

However, choosing 0.002 au as isodensity surface value provides the appearance of $V_{\mathrm{S}, \max }$ on sulfur along the $\mathrm{C}_{\text {pyridyl }}-\mathrm{S}$ bond extension, whereas the $\sigma$-hole along the extension of the $\mathrm{C}_{\mathrm{Me}}-\mathrm{S}$ bond is only observed by using the closer 0.004 au isosurface. This comparison shows that the $0.001 \mathrm{au}$ isosurface is not suitable for computation of $V_{\mathrm{S}, \max }$ on regions of electron charge density depletion located on less polarizable atoms such as sulfur [42]. It is worth mentioning that the 0.002 au isodensity surface has been also preferred with respect to the 0.001 au one in some studies [42-44].

\subsection{Impact of Chemical and Conformational Features on $V_{S}$ Values}

Each conformer is characterized by three variable features: (i) the $\mathrm{Ch}$ atom ( $\mathrm{S}$ or $\mathrm{Se}$ ), (ii) the $\mathrm{R}$ group on $\mathrm{Ch}\left(\mathrm{Me}, \mathrm{Ph}\right.$ or $\left.\mathrm{C}_{6} \mathrm{~F}_{5}\right)$, (iii) the conformational motif (A1, $\mathrm{A} 2, \mathrm{~B} 1$, or $\left.\mathrm{B} 2\right)$. On the contrary, all conformers contain the 5,5'-dibromo-2,2'-dichloro-4,4'-bipyridyl as fixed motif. The impact of the structural (chemical + conformational) features on $\sigma$ - and $\pi$-holes was estimated by calculating for each hole the variation range of $V_{\mathrm{S}, \max }\left(\Delta V_{\mathrm{S}, \max }\right)$ (Table 1). It was found to increase following the order $2^{\prime}-\mathrm{Cl}<5$ - $\mathrm{Br}<5^{\prime}-\mathrm{Br}<2-\mathrm{Cl}<3-\mathrm{Ch}\left(\mathrm{C}_{\mathrm{pyr}}-\mathrm{Ch}\right.$ bond $)<3$ - $\mathrm{Ch}\left(\mathrm{C}_{\mathrm{R}}-\mathrm{Ch}\right.$ bond $)<\pi$-hole. 


\subsection{1. $\sigma$-Holes Located on the Elongation of $\mathrm{C}-\mathrm{X}$ Bonds $(\mathrm{X}=\mathrm{Cl}, \mathrm{Br})$}

As expected, the $V_{S \text {, max }}$ values are more positive for bromine $\sigma$-holes compared to chlorine ones due to the higher polarizability and lower electronegativity of $\mathrm{Br}\left(3.05 \times 10^{-24} \mathrm{~cm}^{3}\right.$ and 2.96 ,

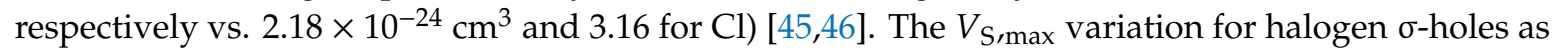
the $\mathrm{R}$ group changes follows the order $\mathrm{Ph}<\mathrm{Me}<\mathrm{C}_{6} \mathrm{~F}_{5}$ in almost all cases. In general, more positive $V_{\mathrm{S} \text { max }}$ values for halogen $\sigma$-holes were found in compounds 1-3 compared to 4-6. This trend reflects the higher electron-attracting power of sulfur compared to selenium, the Pauling electronegativity [45] of sulfur (2.58) being slightly higher than that of selenium (2.55). The effect of Ch electronegativity makes $V_{\text {S,max }}$ more positive on chlorine and bromine $\sigma$-holes which are located on the same ring of the $\mathrm{Ch}$ atom (pyr ring) with respect to the two halogen $\sigma$-holes on the other ring (pyr' ring). Some observed deviations from this trend are likely due to through-space effects related to the position of positive and negative regions on the 3 substituents as the conformational motif changes. In fact, for the $\sigma$-holes located at the elongations of the $\mathrm{C} 2-\mathrm{Cl}$ and $\mathrm{C}^{\prime}-\mathrm{Br}$ bonds, the $V_{\mathrm{S} \text {,max }}$ values could be affected by the proximity of either the R group (conformers A2 and B2) or the $\sigma$-hole on the elongation of the $\mathrm{C}_{\mathrm{R}}-\mathrm{Ch}$ bonds (conformers $\mathrm{A} 1$ and B1). In contrast, $V_{\mathrm{S} \text {,max }}$ of $\sigma$-holes located at the elongations of the $\mathrm{C} 2^{\prime}-\mathrm{Cl}\left(\Delta V_{\mathrm{S}, \max }=0.0046 \mathrm{au}\right)$ and $\mathrm{C} 5-\mathrm{Br}\left(\Delta V_{\mathrm{S}, \max }=0.0055 \mathrm{au}\right)$ bonds show to be less affected by structural changes due to the fact that their environment remains almost unchanged as chemical and conformational features change.

\subsubsection{Phenyl $\pi$-Holes}

The $\pi$-holes on the phenyl ring of compounds 2, 3, 5, and 6 are deeply affected by the electron-attracting power of the substituents on the phenyl ring $\left(\mathrm{C}_{6} \mathrm{H}_{5} \mathrm{vs} \mathrm{C}_{6} \mathrm{~F}_{5}\right)$. Indeed, positive $V_{\mathrm{S} \text {,max }}$ are only observed on the pentafluoro-substituted phenyl ring (compounds 3 and 6), whereas negative values were computed for the phenyl ring in $\mathbf{2}$ and 5. Following the electronegativity scale, the sulfur atom at the 3-position in compound 3 exerts a slightly stronger electron-attracting effect on the pentafluorophenyl ring compared to selenium atom in compound 6. Accordingly, the $\pi$-hole $V_{\mathrm{S} \text {,max }}$ in compound 3 (average values $0.0461 \mathrm{au}$ ) is just slightly more positive than the $\pi$-hole $V_{\mathrm{S} \text {,max }}$ observed in compound 6 (average values $0.0448 \mathrm{au}$ ). For comparison purpose, we computed the $\pi$-hole $V_{\mathrm{S}, \max }$ of the 5,5'-dibromo-2-2'-dichloro-3-(perfluorophenyl)methyl-4,4'-bipyridine (7, see Supplementary Information for details) which bears a $\mathrm{CH}_{2}$ unit in place of the $\mathrm{Ch}$ atom. For 7 , the $\pi$-hole $V_{\mathrm{S} \text {,max }}$ becomes less positive (average values $0.0401 \mathrm{au}$ ) with respect to the $V_{\mathrm{S} \text {,max }}$ computed for the (perfluorophenyl)selanyl derivative 6 even if the same electronegativity is given for both Se and $C$ (2.55). This trend could be rationalized in terms of atomic polarizabilities, selenium being more polarizable $\left(3.77 \times 10^{-24} \mathrm{~cm}^{3}\right)$ than carbon $\left(1.76 \times 10^{-24} \mathrm{~cm}^{3}\right)$ [46], and for this reason more prone to accommodate the gain of electron charge density [16].

$V_{\mathrm{S} \text { max }}$ regions are found above and below the planar phenyl rings in almost all cases. In particular, the $\pi$-hole regions are located on the phenyl face far from (external) and close to (internal) the $4,4^{\prime}$-bipyridine scaffold, respectively. These two $V_{\mathrm{S} \text {,max }}$ regions are not equal because the face close to the bipyridine framework (internal) is more affected by the features of different conformational motifs. Consequently, considering compounds 3 and 6, the $V_{\mathrm{S} \text {, max }}$ of the external region varies over a short range (0.0018 and $0.0017 \mathrm{au}$, respectively), whereas the $V_{\mathrm{S} \text {,max }}$ of the internal region covers a wider range (0.0134 and 0.0137 au, respectively). In particular, two extreme situations can be observed. Indeed, in conformers 3-A2 and 6-A2 no $V_{\mathrm{S} \text {,max }}$ was found in the internal side of the aromatic ring. This phenomenon may be due to the overlapping of the negative $V$ located on the side of the bromine at position $5^{\prime}$. In this case, the $V_{\mathrm{S}, \max }$ value is affected by a through-space effect [15] determined by an intramolecular Br $\cdots \pi$-hole contact. In contrast, for compounds $\mathbf{3}$ and $\mathbf{6}$ the highest $\pi$-hole $V_{\mathrm{S} \text { max }}$ values are observed for conformers A1 and B1 because the phenyl ring is far from the $5^{\prime}$-bromine and, consequently, does not undergo any saturation effect. 


\subsubsection{3-Ch $\sigma$-Holes}

In principle, in compounds 1-6, the Ch atoms can bear two $\sigma$-holes on the elongation of the $\mathrm{C}_{\text {pyridyl }}-\mathrm{Ch}$ and $\mathrm{C}_{\mathrm{R}}-\mathrm{Ch}$ bonds. In general, the main factors affecting the $\sigma$-hole $V$ of a given R-Ch-R' system are electronegativity and polarizability of $\mathrm{Ch}$ as well as the electron-attracting power and the polarizability of $\mathrm{R}$ and $\mathrm{R}^{\prime}$ [16]. In all considered conformers, the $V_{\mathrm{S} \text {, max }}$ values are more positive for selanyl compounds $\mathbf{4} \mathbf{- 6}$ compared to the thio-substituted series $\mathbf{1}-\mathbf{3}$. This trend is due to the higher polarizability $\left(3.77 \times 10^{-24} \mathrm{~cm}^{3}\right)$ [46] and lower electronegativity (2.55) of selenium with respect to sulfur $\left(2.90 \times 10^{-24} \mathrm{~cm}^{3} ; 2.58\right)$. For the $\sigma$-hole located on the elongation of the $\mathrm{C}_{\text {pyridyl }}-\mathrm{Ch}, V_{\mathrm{S} \text { max }}$ values vary following the order $\mathrm{Ph}<\mathrm{Me}<\mathrm{C}_{6} \mathrm{~F}_{5}$, whereas high variability is observed for the other $\sigma$-hole. The analysis of the $V_{\mathrm{S}, \max }$ reported in Table 1 shows that in conformers A1 and B1 of compounds 2, 3, 5, and 6, $V_{\mathrm{S} \text {,max }}$ values on $\mathrm{Ch}$ are more positive for the $\mathrm{C}_{\text {pyridyl }}-\mathrm{Ch} \sigma$-holes compared to the other $\sigma$-holes located on the elongation of the $\mathrm{C}_{\mathrm{R}}-\mathrm{Ch}$ bonds. The opposite situations occur for conformers A2 and B2. Therefore, based on the trend observed for A2 and B2, the electron-attracting power (or/and polarizability) of the aryl rings is higher than that of the $4,4^{\prime}$-bipyridyl scaffold. Thus, in A1 and B1, a decrease of $V_{\mathrm{S} \text {,max }}$ occurs for the $\sigma$-hole located on the elongation of the $\mathrm{C}_{\mathrm{R}}-\mathrm{Ch}$ bonds. Considering 6-B1 and 6-B2 as representative cases (Figure 3), the question seems to be related to the impact of the conformation environment on the $C_{R}-$ Se $\sigma$-hole. In fact, in 6-B1 (Figure 3, left), the $C_{A r F}-$ Se $\sigma$-hole is oriented toward the $5^{\prime}$-bromine atom which contributes to decrease the $V_{\mathrm{S} \text {,max }}$ of the hole by partially saturating the neighboring positive region through the negative electrostatic potential located on the halogen side. This effect does not occur in conformer 6-B2 (Figure 3, right) where the $\mathrm{C}_{\mathrm{ArF}}-\mathrm{Se} \sigma$-hole is oriented toward the small $3^{\prime}$-hydrogen atom. Interestingly, the unusual presence of two $\sigma$-holes (Figure 4, M1 and M2) on the elongation of the $\mathrm{C}_{\mathrm{ArF}}-\mathrm{Ch}$ bond in conformers 3-B1 and 6-B1 appeared to be related to the features of the B1 motif. As mentioned above, in this conformation the $\sigma$-holes on the elongation of $\mathrm{C}_{\mathrm{ArF}}-\mathrm{Ch}$ bond points towards the cylindrical region of negative $V$ associated with the $\pi$-electron distribution along C-Br bond (the C5'-Br-M1(M2) angle is not far from 90 ${ }^{\circ}$ (Figure 4 and Table 3). This makes the $V_{\mathrm{S} \text {,max }}$ of $\mathrm{C}_{\mathrm{ArF}}-\mathrm{Ch} \sigma$-hole partly counterbalanced by a region of minimal $V$, hence the maxima are forced to displace and split in two maxima M1 and M2. The negative $V$ contribution from the neighboring bromine atom decreases the $V_{\mathrm{S} \text {,max }}$ values on $\mathrm{C}_{\text {ArF }}-\mathrm{Ch}_{\sigma}-\mathrm{hole}$ in 3- and 6-B1 compared to 3- and 6-B2. The $\sigma$-hole splitting phenomenon is rare but not unknown and it was observed in hypervalent iodine [47]. It is interesting to note that as a matter of fact, in conformers 3-B1 and 6-B1, 5'-bromine atom exerts a neighboring group stabilization by Ch $\sigma$-hole [35]. Accordingly, for both 3 and $\mathbf{6}$, the B1motif corresponds to the lowest energy conformers in vacuum.

Table 3. $V_{\mathrm{S}, \max }(\mathrm{au})$ and geometrical parameters of $\sigma$-holes $(\mathrm{M})$ located on the elongation of $\mathrm{C}_{\mathrm{ArF}}-\mathrm{Ch}$ bond in 3-B1, 3-B2, 6-B1, and 6-B2.

\begin{tabular}{|c|c|c|c|c|c|}
\hline Conf.,M & $V_{S, \text { max }}(\mathrm{au})$ & $\mathrm{d}_{\mathrm{Ch}-\mathrm{M}}(\AA)$ & $\mathrm{d}_{\mathrm{Br}-\mathrm{M}}(\AA)$ & $\mathrm{C} 5^{\prime}-\mathrm{Br}-\mathrm{M}\left({ }^{\circ}\right)$ & $\mathrm{C}_{\mathrm{ArF}}-\mathrm{Br}-\mathrm{M}\left(^{\circ}\right)$ \\
\hline 3-B1, $\mathrm{M}_{1}$ & 0.0202 & 2.098 & 2.268 & 61.9 & 156.2 \\
\hline $3-\mathrm{B} 1, \mathrm{M}_{2}$ & 0.0272 & 2.016 & 2.431 & 87.2 & 154.5 \\
\hline 3-B2,M & 0.0553 & 2.095 & $1.616^{1}$ & $97.6^{2}$ & 162.7 \\
\hline 6-B1, $\mathrm{M}_{1}$ & 0.0309 & 2.035 & 2.410 & 73.7 & 163.3 \\
\hline 6-B1, $\mathrm{M}_{2}$ & 0.0319 & 2.057 & 2.418 & 88.8 & 154.5 \\
\hline 6-B2,M & 0.0603 & 2.105 & $1.696^{1}$ & $94.6^{2}$ & 161.6 \\
\hline
\end{tabular}




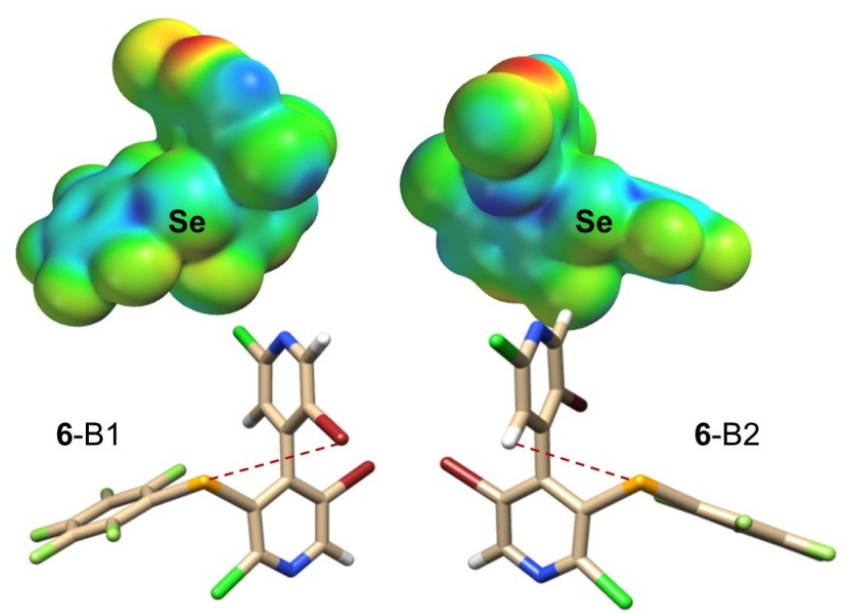

Figure 3. Impact of conformation environment on selenium $\sigma$-holes. Comparison of 6-B1 and 6-B2. Tube structures colors: bromine (red), chlorine (green), fluorine (clear green), hydrogen (white), nitrogen (blue), selenium (orange). $V_{\mathrm{S}}$ representations: colors towards red, negative $V_{\mathrm{S}}$; colors towards blue, positive $V_{\mathrm{S}}$; colors in between (orange, yellow, green), intermediate values of $V_{\mathrm{S}}$.
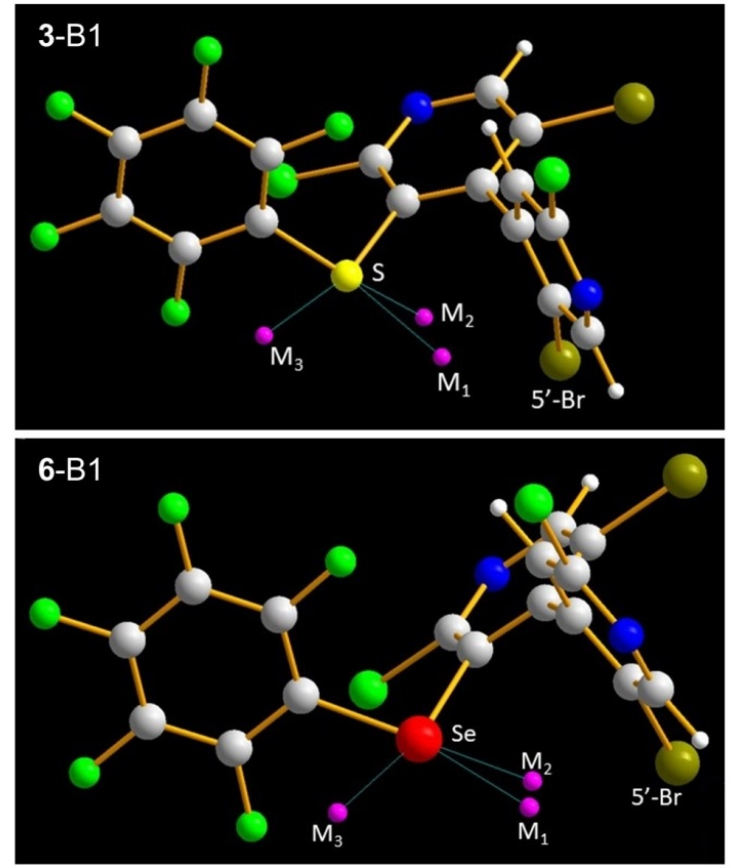

Figure 4. Calculated $\sigma$-holes on the elongation of $\mathrm{C}_{\mathrm{ArF}}-\mathrm{Ch}(\mathrm{M} 1, \mathrm{M} 2)$ and $\mathrm{C}_{\mathrm{Pyr}}-\mathrm{Ch}(\mathrm{M} 3)$ bonds in conformers 3-B1 and 6-B1. Tube structures colors: $\sigma$-holes (pink), bromine (dark green), carbon (grey), chlorine and fluorine (green), hydrogen (white), nitrogen (blue), selenium (red), sulfur (yellow). Pictures were obtained through the code Diamond v3.21. Putz, H. \& Brandenburg, K. (1997-2012). Diamond-Crystal and Molecular Structure Visualization. Crystal Impact, GbR, Kreuzherrenstrasse 102, 53227 Bonn, Germany, http://www.crystalimpact.com/diamond.

A different trend is observed for compounds 1 and 4, likely due to the poor electron-attracting power of the methyl group. In particular, for 1-A2 no $\sigma$-hole on the elongation of $\mathrm{C}_{\mathrm{Me}}-\mathrm{S}$ bond was detectable on the 0.002 isosurface (Table 2). Analogously, no $\sigma$-hole was found in 2-B2 on the elongation of $\mathrm{C}_{\mathrm{Ph}}-\mathrm{S}$ bond.

\subsection{Source Function (SF) Reconstruction of $V_{S, \max }$}

Each $V_{\mathrm{S}, \max }$ value for systems 1-6 may be decomposed as $V_{\mathrm{S}, \max }=\mathrm{SF}(\mathrm{Ch})+\mathrm{SF}(\mathrm{R})+\mathrm{SF}(\mathrm{Bipy})$ $+\operatorname{Err}\left(V_{\mathrm{S}, \mathrm{max}}\right)$, where $\mathrm{SF}(\mathrm{Y})(\mathrm{Y}=\mathrm{Ch}, \mathrm{R}, \mathrm{Bipy})$ denotes the cumulative SF contribution of the $\mathrm{Y}$ 
moiety, and $\operatorname{Err}\left(V_{\mathrm{S}, \max }\right)$ the numerical integration error associated with the $V_{\mathrm{S}, \max }$ SF reconstruction. $V_{\mathrm{S} \text {,max }}$ values and their $\mathrm{SF}(\mathrm{Y})$ contributions to the $\mathrm{C}_{\text {pyridyl }}-\mathrm{Ch}$ and the $\mathrm{C}_{\mathrm{R}}-\mathrm{Ch}(\mathrm{Ch}=\mathrm{S}$, Se) $\sigma$-holes and to the aryl $\pi$-holes, calculated for the various conformers of systems $\mathbf{1 - 6}$, are reported in Tables 4 and 5 ( $\sigma$-holes) and S5 ( $\pi$-holes). For the sake of clarity, two examples of such SF reconstructions for the $\mathrm{C}_{\text {pyridyl }}-\mathrm{Ch} \sigma$-holes and other two for the aryl $\pi$-holes are illustrated in Figures 5 and 6 , respectively. The SF(Y) values were obtained through the ANASFR_EP code (see Section 3) from the atomic SF data. SF data for $3^{\prime}-\mathrm{H}$ and for 5'-Br atoms are listed in Tables 4 and 5, and Table S5 due to the special role the atoms at these positions play, according to the various molecular conformations. In addition, Tables 4 and 5, and Table S5 report the dissection of the SF(Bipy) contribution in its two composing ring contributions, $\mathrm{SF}(p y r)$ and $\mathrm{SF}\left(p_{y} r^{\prime}\right)$ and the SF integration errors. The latter are listed as percentage SF reconstruction errors for each $V_{\mathrm{S}, \max }$ value, $\operatorname{Err} \%\left(V_{\mathrm{S}, \max }\right)=\left[\left(\mathrm{SF}(\mathrm{Ch}+\mathrm{R}+\mathrm{Bipy})-V_{\mathrm{S}, \max }\right) / V_{\mathrm{S}, \max }\right] \times 100$.

Table 4. $\quad V_{\mathrm{S}, \max }(\mathrm{au})$ and their Source Function (SF) atomic group contributions on $\mathrm{C}_{\text {pyridyl }}-\mathrm{Ch}$ ( $\mathrm{Ch}=\mathrm{S}$, Se) $\sigma$-holes (0.002 au molecular surface) calculated for the various conformers of systems 1-6. In parentheses the SF percentage values are reported. The Err\% value (see text) provides a measure of the $\mathrm{SF} V_{\mathrm{S} \text {, max }}$ reconstruction accuracy.

\begin{tabular}{|c|c|c|c|c|c|c|c|c|c|}
\hline Conf. & $V_{\mathrm{S}, \max }$ & SF(Ch) & $\mathrm{SF}(\mathrm{R})$ & SF(BiPy) & $\mathrm{SF}(p y r)$ & $\mathrm{SF}\left(p y r^{\prime}\right)$ & $\mathrm{SF}\left(5^{\prime}-\mathrm{Br}\right)$ & $\mathrm{SF}\left(3^{\prime}-\mathrm{H}\right)$ & Err\% \\
\hline \multicolumn{10}{|c|}{ S ( $\sigma$-hole, Cpyridyl-S) } \\
\hline 1-A1 & 0.0428 & $0.0345(80.7)$ & $0.0173(40.4)$ & $-0.0077(-18.1)$ & $-0.0120(-28.0)$ & $0.0042(9.9)$ & $-0.0016(-3.8)$ & $0.0101(23.6)$ & 3.0 \\
\hline 1-A2 & 0.0423 & $0.0324(76.5)$ & 0.0185 (43.9) & $-0.0071(-16.8)$ & $-0.0118(-28.0)$ & 0.0047 (11.2) & $-0.0028(-6.6)$ & $0.0106(25.1)$ & 3.6 \\
\hline 2-B1 & 0.0307 & $0.0369(120.2)$ & $0.0006(2.0)$ & $-0.0058(-19.1)$ & $-0.0100(-32.6)$ & $0.0041(13.5)$ & $-0.0022(-7.1)$ & $0.0099(32.3)$ & 3.1 \\
\hline 2-A2 & 0.0267 & $0.0340(127.0)$ & $-0.0027(-9.9)$ & $-0.0038(-14.3)$ & $-0.0095(-35.5)$ & $0.0057(21.3)$ & $-0.0000(-0.0)$ & $0.0118(44.0)$ & 2.9 \\
\hline $2-B 2$ & 0.0286 & $0.0352(123.1)$ & $-0.0007(-2.5)$ & $-0.0056(-19.4)$ & $-0.0104(-36.4)$ & $0.0049(17.0)$ & $-0.0018(-6.2)$ & $0.0111(38.9)$ & 1.1 \\
\hline $3-\mathrm{A} 2$ & 0.0491 & $0.0639(130.2)$ & $-0.0186(-37.9)$ & $0.0040(8.2)$ & $-0.0026(-5.3)$ & 0.0067 (13.5) & $-0.0012(-2.5)$ & $0.0156(31.2)$ & 0.5 \\
\hline 3-B2 & 0.0512 & $0.0656(128.3)$ & $-0.0161(-31.4)$ & 0.0019 (3.6) & $-0.0046(-9.0)$ & $0.0064(12.6)$ & $0.0009(1.8)$ & $0.0111(21.6)$ & 0.5 \\
\hline \multicolumn{10}{|c|}{ Se ( $\sigma$-hole, Cpyridyl-Se) } \\
\hline 4-A1 & 0.0521 & $0.0897(172.2)$ & $-0.0122(-23.5)$ & $-0.0240(-46.0)$ & $-0.0275(-52.7)$ & $0.0035(6.7)$ & $-0.0021(-4.1)$ & $0.0100(19.3)$ & 2.7 \\
\hline 4-A2 & 0.0518 & $0.0877(169.4)$ & $-0.0108(-20.9)$ & $-0.0239(-46.3)$ & $-0.0276(-53.4)$ & 0.0037 (7.1) & $-0.0026(-5.1)$ & $0.0102(19.8)$ & 2.3 \\
\hline 5-A1 & 0.0401 & $0.0941(234.8)$ & $-0.0318(-79.2)$ & $-0.0213(-53.1)$ & $-0.0253(-63.1)$ & $0.0040(10.0)$ & $-0.0018(-4.6)$ & $0.0112(28.1)$ & 2.4 \\
\hline
\end{tabular}

Table 5. $V_{\mathrm{S}, \max }(\mathrm{au})$ and their Source Function $(\mathrm{SF})$ atomic group contributions on $\mathrm{C}_{\mathrm{R}}-\mathrm{Ch}(\mathrm{Ch}=\mathrm{S}$, Se) $\sigma$-holes (0.002 au molecular surface) calculated for the various conformers of systems 1-6. In parentheses the SF percentage values are reported. The Err\% value (see text) provides a measure of the SF $V_{\mathrm{S} \text {, max }}$ reconstruction accuracy.

\begin{tabular}{|c|c|c|c|c|c|c|c|c|c|}
\hline Conf. & $V_{\mathrm{S}, \max }$ & SF(Ch) & SF(R) & SF(BiPy) & SF(pyr) & $\mathrm{SF}\left(p y r^{\prime}\right)$ & $\mathrm{SF}\left(5^{\prime}-\mathrm{Br}\right)$ & $\mathrm{SF}\left(3^{\prime}-\mathrm{H}\right)$ & Err $\%$ \\
\hline \multicolumn{10}{|c|}{$\mathrm{S}\left(\sigma\right.$-hole, $\left.\mathrm{C}_{\mathrm{R}}-\mathrm{S}\right)$} \\
\hline 1-A1 & 0.0193 & $0.0312(161.1)$ & $0.0107(55.1)$ & $-0.0215(-111.1)$ & $-0.0286(-147.6)$ & $0.0071(36.5)$ & $-0.0150(-77.4)$ & $0.0114(58.7)$ & 5.1 \\
\hline 1-A2 & Absent & & & & & & & & \\
\hline 2-B1 & 0.0169 & $0.0342(202.8)$ & $0.0041(24.6)$ & $-0.0204(-120.7)$ & $-0.0263(-155.8)$ & $0.0059(35.1)$ & $-0.0166(-98.1)$ & $0.0115(68.0)$ & 6.7 \\
\hline 2-A2 & 0.0340 & $0.0385(113.2)$ & 0.0049 (14.5) & $-0.0085(-25.0)$ & $-0.0294(-86.6)$ & $0.0210(61.7)$ & $0.0008(2.3)$ & $0.0168(49.3)$ & 2.8 \\
\hline 2-B2 & Absent & & & & & & & & \\
\hline 3-B1 & 0.0202 & 0.0267 (132.2) & $-0.0121(-59.7)$ & $0.0062(30.9)$ & $-0.0004(-2.2)$ & $0.0067(33.2)$ & $-0.0064(-31.8)$ & $0.0153(75.9)$ & 3.4 \\
\hline 3-A2 & 0.0500 & 0.0607 (121.2) & $-0.0121(-24.1)$ & $0.0019(3.8)$ & $-0.0175(-35.0)$ & $0.0194(38.8)$ & $-0.0006(-1.1)$ & $0.0119(24.3)$ & 0.9 \\
\hline 3-B2 & 0.0553 & $0.0523(94.6)$ & $-0.0107(-19.4)$ & $0.0144(26.0)$ & $-0.0162(-29.4)$ & $0.0306(55.4)$ & $0.0044(7.9)$ & $0.0262(47.4)$ & 1.2 \\
\hline \multicolumn{10}{|c|}{ Se $\left(\sigma\right.$-hole, $C_{R}-$ Se $)$} \\
\hline 4-A1 & 0.0260 & $0.0784(302.0)$ & $-0.0057(-22.1)$ & $-0.0457(-176.0)$ & $-0.0495(-190.4)$ & $0.0037(14.4)$ & $-0.0167(-64.3)$ & $0.0115(44.4)$ & 3.9 \\
\hline 4-A2 & 0.0463 & $0.0810(175.0)$ & $-0.0048(-10.4)$ & $-0.0290(-62.7)$ & $-0.0516(-111.4)$ & $0.0225(48.7)$ & $0.0011(2.4)$ & $0.0235(50.8)$ & 1.8 \\
\hline 6-B1 & 0.0319 & $0.1011(317.0)$ & $-0.0288(-90.4)$ & $-0.0400(-125.6)$ & $-0.0425(-133.4)$ & $0.0025(7.7)$ & $-0.0195(-61.3)$ & $0.0130(40.6)$ & 0.9 \\
\hline 6-A2 & 0.0609 & 0.1176 (193.1) & $-0.0288(-47.4)$ & $-0.0272(-44.7)$ & $-0.0444(-72.9)$ & $0.0172(28.2)$ & $-0.0007(-1.2)$ & $0.0149(24.5)$ & 1.0 \\
\hline 6-B2 & 0.0603 & 0.1059 (175.5) & $-0.0284(-47.1)$ & $-0.0161(-26.8)$ & $-0.0391(-64.9)$ & $0.0230(38.1)$ & $0.0043(7.2)$ & $0.0254(42.1)$ & 1.7 \\
\hline
\end{tabular}


0.12

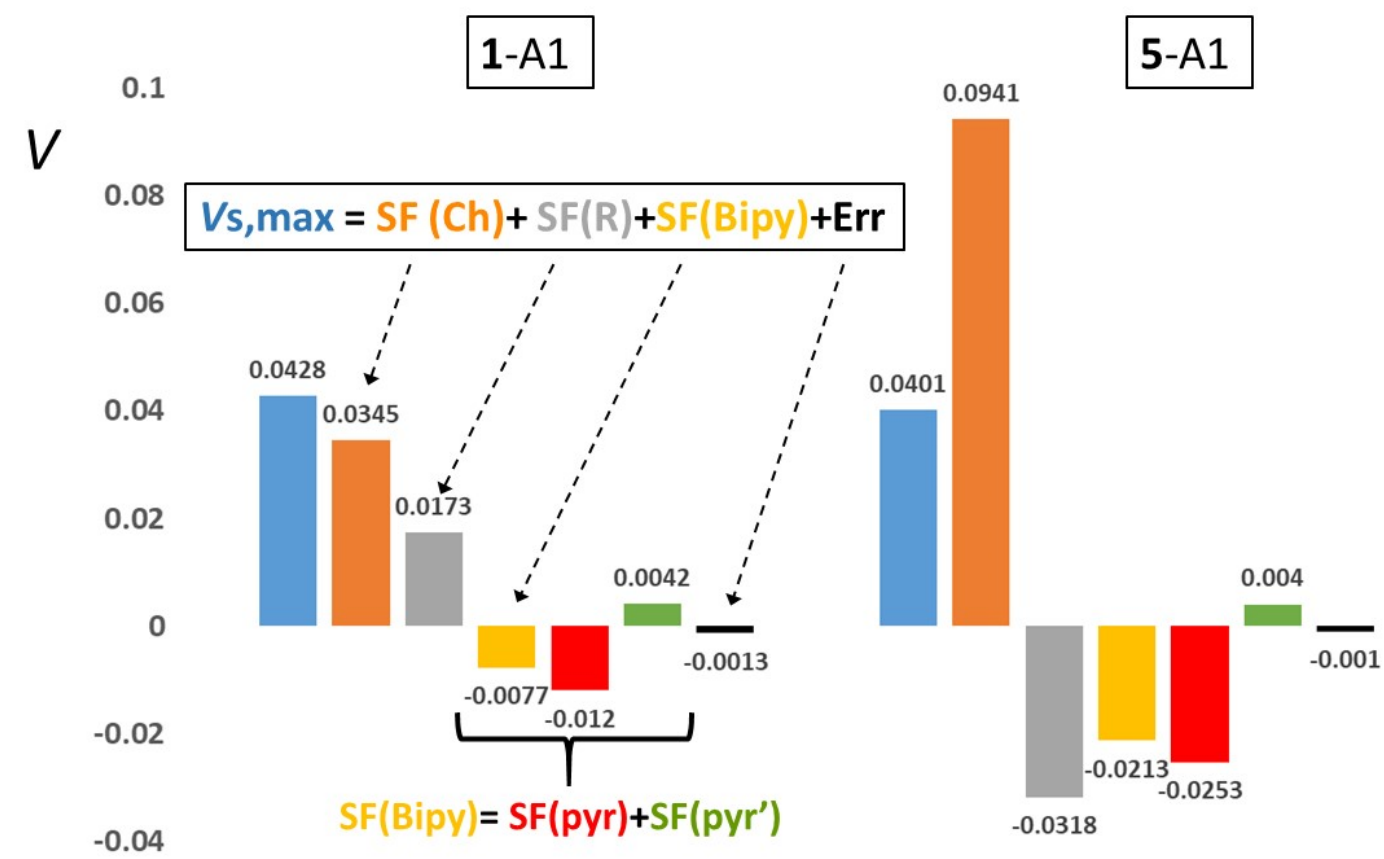

Figure 5. $V_{S, \max }(\mathrm{au})$ Source Function (SF) decomposition in two exemplar $\sigma$-hole cases (see Tables 4 and 5 for the full list of cases and SF decomposition data). Data refer to the $\mathrm{C}_{\text {pyridyl }}-\mathrm{Ch} \sigma$-holes $(\mathrm{Ch}=\mathrm{S}$ and Se for 1-A1 $(\mathrm{R}=\mathrm{Me})$ and 5-A1 $(\mathrm{R}=\mathrm{Ph})$ molecules, respectively). The two molecules have very close $V_{\mathrm{S}, \max }$ values, yet the roles of the $\mathrm{Ch}, \mathrm{R}$, and Bipy moieties in producing such values are strikingly different. The SF from the Bipy moiety, SF(Bipy), is also shown as dissected into its two composing ring contributions $\mathrm{SF}(p y r)$ and $\mathrm{SF}\left(p y r^{\prime}\right)$.

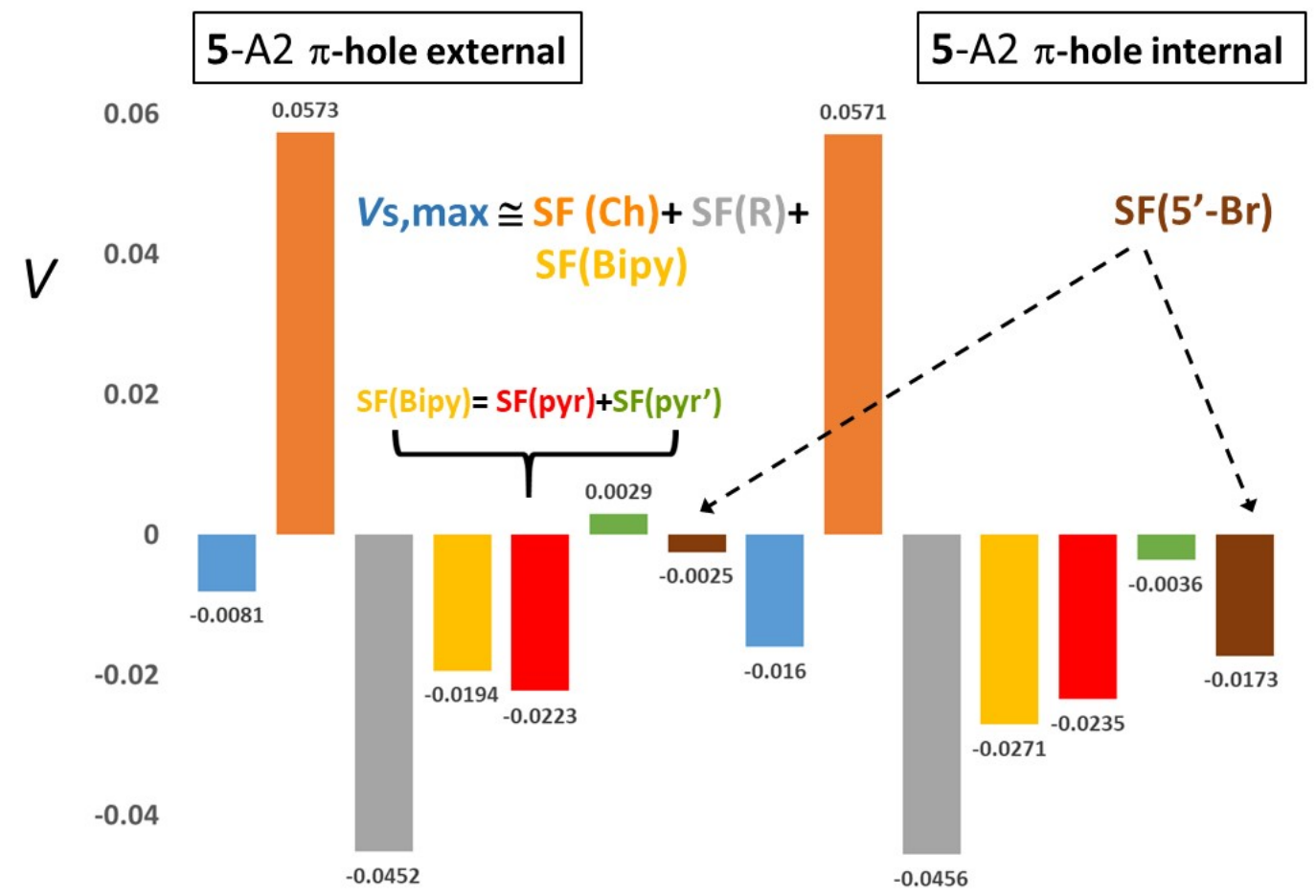

Figure 6. $V_{\mathrm{S}, \max }(\mathrm{au})$ Source Function (SF) decomposition in two exemplar aryl $\pi$-holes (see Table S5 for the full list of cases and SF decomposition data). Data refer to the external (left) and internal (right) aryl $\pi$-holes (0.002 au molecular surface) calculated for the 5-A2 conformer. For most of the investigated systems in this work, the internal and the external $\pi$-holes are hardly distinguishable as for their $V_{\mathrm{S}, \max }$ 
value, but for the 5-A2 conformer the internal $\pi$-hole has twice the $V_{\mathrm{S} \text {, } \max }$ magnitude of the external one. $\mathrm{SF}$ contributions from the $\mathrm{Ch}=\mathrm{Se}$ and $\mathrm{R}=$ Phenyl are almost equal for the two holes, while SF(Bipy) is the responsible for their $V_{\mathrm{S} \text {, max }}$ difference and essentially because of the different $\mathrm{SF}$ contribution from its $p y r^{\prime}$ ring, hosting the $5^{\prime}-\mathrm{Br}$ atom. This atom points its $\pi$-cloud towards the phenyl ring internal $\pi$-hole making this hole largely more negative (see text).

\subsection{1. $\mathrm{C}_{\text {pyridyl }}-\mathrm{Ch} \sigma$-Holes}

With reference to the decomposition of such hole potentials (Table 4) into $\mathrm{Ch}, \mathrm{R}$ and Bipy SF contributions, one notices that the $V_{\mathrm{S} \text {,max }}$ values are largely dominated by the $\mathrm{SF}(\mathrm{Ch})$ positive contribution. In particular, the one due to $S e$ is about twice as large as that due to the $S$ atom, for a given $\mathrm{R}$ and conformation. The $\mathrm{SF}(\mathrm{Ch})$ contribution is in most cases even larger than the $V_{\mathrm{S} \text {,max }}$ value and ranges, in percentage, from $76 \%$ to $134 \%$ for $\mathrm{Ch}=\mathrm{S}$, and from $169 \%$ to $234 \%$ for $\mathrm{Ch}=\mathrm{Se}$, depending on the conformation. This roughly doubled effect (in absolute value and in percentage) of the Se is not surprising, due to the lower electronegativity and thus the larger positive charge of Se relative to $S$ (see infra). Conversely, this same reason increases the electronic charge on the $\mathrm{R}$ group. It so lowers the $\mathrm{SF}(\mathrm{R})$ contribution, changing it from moderately positive (1-A1, 1-A2) to moderately negative (4-A1, 4-A2) or from negligibly negative (2-A1, 2-A2, 2-B2) or moderately negative (3, all conformers) to largely negative (5 and $\mathbf{6}$, all conformers) on passing from $\mathrm{Ch}=\mathrm{S}$ to $\mathrm{Ch}=\mathrm{Se}$. The trend $\mathrm{SF}(\mathrm{Me})>$ $\mathrm{SF}(\mathrm{Ph})>\mathrm{SF}\left(\mathrm{C}_{6} \mathrm{~F}_{5}\right)$ holds true for both $\mathrm{Ch}=\mathrm{S}$ and $\mathrm{Ch}=\mathrm{Se}$ and mirrors the trends of the Bader's net charges $q$ of the $\mathrm{R}$ group or, though understandably reversed, the trend of the positive Bader's net charge on the $\mathrm{Ch}$ atom. For instance, for the A1 conformers, the $\mathrm{q}(\mathrm{R})$ charges decrease from $0.055(\mathrm{Me})$, through $-0.001(\mathrm{Ph})$, to $-0.149\left(\mathrm{C}_{6} \mathrm{~F}_{5}\right)$ for $\mathrm{Ch}=\mathrm{S}$ and from $-0.038(\mathrm{Me})$, through $-0.088(\mathrm{Ph})$, to -0.251 (C6F5), for $\mathrm{Ch}=\mathrm{Se}$, while the $\mathrm{q}(\mathrm{Ch})$ charges increase from 0.091 (1-A1), through 0.122 (2-A1), to 0.209 (3-A1) for $\mathrm{Ch}=\mathrm{S}$ and from 0.278 (4), through 0.315 (5), to 0.410 (6) for $\mathrm{Ch}=\mathrm{Se}$.

Analogously to the $\mathrm{SF}(\mathrm{R})$ contribution, also the SF contribution of the Bipy moiety decreases with the decrease of $\mathrm{Ch}$ electronegativity. For $\mathrm{Ch}=\mathrm{Se}$ and for a given $\mathrm{R}, \mathrm{SF}(\mathrm{Bipy})$ is always negative and greater in magnitude relative to $\mathrm{Ch}=\mathrm{S}$. For a given chalcogen, the $\mathrm{SF} \%($ Bipy) values are similar for $\mathrm{R}=\mathrm{Me}$ or $\mathrm{Ph}$ (ranging from $-14 \%$ to $-20 \%$ for $\mathrm{Ch}=\mathrm{S}$ and from $-46 \%$ to $-54 \%$ for $\mathrm{Ch}=\mathrm{Se}$ ), while the much larger electron-withdrawing power of the $\mathrm{R}=\mathrm{C}_{6} \mathrm{~F}_{5}$ group, shifts $\mathrm{SF} \%$ (Bipy) to slightly positive values ( $4 \%$ to $9 \%$ ) or to less negative values (about $-26 \%$ ) for $\mathrm{Ch}=\mathrm{S}$ and $\mathrm{Ch}=\mathrm{Se}$, respectively. Although the positive $\mathrm{SF}(\mathrm{Ch})$ contributions always dominate the other two SF contributions to the $V_{\mathrm{S} \text {,max }}$ values, the relative magnitude of the generally negative (or seldom negligibly positive) $\mathrm{SF}(\mathrm{Bipy})$ and $\mathrm{SF}(\mathrm{R})$ contributions obviously depends on the $\mathrm{R}$ group and on the Ch type.

In particular, for $\mathrm{Ch}=\mathrm{S}$, the $\mathrm{SF}\left(\mathrm{R}, \mathrm{R}=\mathrm{Me}\right.$ or $\left.\mathrm{C}_{6} \mathrm{~F}_{5}\right)$ value is from 2 to 10 times larger in magnitude than the $\mathrm{SF}$ (Bipy) value, while for $\mathrm{R}=\mathrm{Ph}$ both contributions are small. However, $\mathrm{SF}(\mathrm{Bipy})$ is larger in magnitude than $\mathrm{SF}(\mathrm{Ph})$, which is negligibly negative or negligibly positive, depending on the conformer. Conversely, for $\mathrm{Ch}=\mathrm{Se}$, the $\mathrm{SF}(\mathrm{R})$ and $\mathrm{SF}$ (Bipy) contributions are more alike to each other in magnitude and always negative, hence they are always opposing the $\mathrm{SF}(\mathrm{Se})$ contribution. For $\mathrm{Ch}=\mathrm{Se}, \mathrm{SF}(\mathrm{Bipy})$ is twice as large in magnitude than $\mathrm{SF}(\mathrm{Me})$, while it is $2 / 3$ (5, all conformers) or $1 / 3$ (6, all conformers) smaller in magnitude than $\mathrm{SF}(\mathrm{R})$ for $\mathrm{R}=\mathrm{Ph}$ or $\mathrm{C}_{6} \mathrm{~F}_{5}$, respectively. Dissection of the Bipy source in the contribution from the pyr and pyr' ring moieties provides further insight. Regardless of the $\mathrm{R}$ group, of the system conformation and of the nature of $\mathrm{Ch}$, the source from the pyr ring carrying the chalcogen atom is always negative, while that of $p y r^{\prime}$ ring is invariably positive. The magnitude of the source from the pyr ring significantly increases on passing from $S$ to Se, becoming largely negative and bounded to a limited range of values $(-0.020 /-0.028 \mathrm{au})$, while that from the $p y r^{\prime}$ ring remains relatively small and in the range of $0.0035 / 0.0064$ au for both $\mathrm{Ch}=\mathrm{S}$ and $\mathrm{Ch}=\mathrm{Se}$. The different sign of the two ring sources, along with the large impact that the chalcogen nature has on the negative source of the pyr ring is a clear indication of the electron-donor effect of the chalcogen substituent on such ring. The SF contributions to the $\mathrm{C}_{\text {pyridyl }}-\mathrm{Ch} \sigma$-holes from the $3^{\prime}-\mathrm{H}$ and $5^{\prime}$ - $\mathrm{Br}$ atoms are almost constant for all 1-6 conformers, confirming that for such holes, due to their spatial location and at variance with the case of the $C_{R}-C h$-holes, the molecular conformation does not play any role. We conclude the 
discussion of Table 4 by noting that the percentage integration errors, Err\%, are not negligible and occasionally large (3-4\%) but generally lower than 1-2\%. A similar comment holds true also for most of holes in Table 5 and Table S5. Yet, the SF reconstruction of the phenyl $\pi$-holes with negative and small in magnitude $(<0.01 \mathrm{au}) V_{\mathrm{S}, \max }$ values, is by far less accurate $($ Err\%: $3-13 \%)$.

\subsection{2. $\mathrm{C}_{\mathrm{R}}-\mathrm{Ch} \sigma$-Holes}

Likewise the $\mathrm{C}_{\text {pyridyl }}-\mathrm{Ch} \sigma$-holes, also the $V_{\mathrm{S} \text {,max }}$ values of the $\mathrm{C}_{\mathrm{R}}-\mathrm{Ch} \sigma$-holes (Table 5) are largely dominated by the positive $\mathrm{SF}(\mathrm{Ch})$ contribution, with those of Se being on average roughly twice as big as those from the $S$ in magnitude. Although the $S F(C h)$ percentage contributions for the $C_{R}-C h$ $\sigma$-holes are scattered over larger ranges of values (SF(S)\%, 95-203; SF(Se)\%, 175-317), compared to the case of the $\mathrm{C}_{\text {pyridyl }}-\mathrm{Ch} \sigma$-holes (SF(S)\%, 80-134; $\left.\mathrm{SF}(\mathrm{Se}) \%, 169-235\right)$, the magnitudes of SF contributions do follow similar qualitative trends $\left(C_{R}-C h\right.$-holes: 1 and 2, 0.03/0.04 au, 3, 0.05/0.06 au, 4 and 5, 0.08/0.09 au, 6, 0.08/0.12 au; $\mathrm{C}_{\text {pyridyl }}-\mathrm{Ch}$ o-holes: 1 and 2, 0.03/0.04 au, 3, 0.06/0.07 au; 4 and 5, 0.09 au, 6, $0.12 \mathrm{au}$; note that for 3-B1, with two $\mathrm{C}_{\mathrm{R}}-\mathrm{Ch} \sigma$-holes, the hole with the higher $V_{\mathrm{S} \text {,max }}$ value was here considered). Given these similarities between the $S F(C h)$ values and trends of the $C_{R}-C h$ and $\mathrm{C}_{\text {pyridyl }}-\mathrm{Ch} \sigma$-holes, analogous interpretations to those put forward for Table 4 also hold for the case of $\mathrm{C}_{\mathrm{R}}$-Ch holes in Table 5. The cumulative source of the Bipy and the R moieties generally opposes the source from the $\mathrm{Ch}$ atom, apart one single case (3-B2) where it slightly (7\%) concurs to the overall $V_{\mathrm{S}, \max }$ value of the $C_{R}-C h$-hole. The way they oppose is very much dependent on the system and on its conformation. It may be just a small opposition as for systems $2-\mathrm{A} 2$ and 3-A2 (-11/-20\%) or definitely a far larger one as for the two 6-B1 holes $(-171 /-216 \%)$ or the 4-A1 and 5-A1 holes $(-198 /-162 \%)$. The Bipy and the $\mathrm{R}$ groups may either cooperate or oppose each other in their action as the ratio of their contributing sources ranges from -6.3 to 2.5 , depending on systems and their conformers. Despite such a variety of behaviors, there are some general trends worth to be mentioned. In the case of $\mathrm{Ch}=\mathrm{Se}$, the SF contribution for both Bipy and $\mathrm{R}$ moieties is invariably negative (as it is for the $\mathrm{C}_{\text {pyridyl }}-\mathrm{Ch} \sigma$-holes), with that of the Bipy generally and significantly prevailing in magnitude over the $\mathrm{Me}$ and $\mathrm{Ph}$ for systems 4 and 5. Instead, when $\mathrm{R}=\mathrm{C}_{6} \mathrm{~F}_{5}$, it is the negative source of this group which is larger in magnitude in three out of the five reported cases. Analogously to the case of the $\mathrm{C}_{\text {pyridyl }}-\mathrm{Ch}$ $\sigma$-holes, the $\mathrm{SF}(\mathrm{R})$ values follow the trend $\mathrm{SF}(\mathrm{Me})>\mathrm{SF}(\mathrm{Ph})>\mathrm{SF}\left(\mathrm{C}_{6} \mathrm{~F}_{5}\right)$ for both $\mathrm{Ch}=\mathrm{Se}$ and $\mathrm{S}$, due to the corresponding increase of the net negative charge of the $\mathrm{R}$ group along the series. For $\mathrm{Ch}=\mathrm{S}$, $\operatorname{SF}(R)$ is positive $(R=M e)$ or still positive but smaller $(R=P h)$, while it is negative $(-19 /-59 \%)$ for $\mathrm{R}=\mathrm{C}_{6} \mathrm{~F}_{5}$. Regarding the distinct contributions from the two rings of the Bipy moiety, some of the considerations reported for the $\mathrm{C}_{\text {pyridyl }}-\mathrm{Ch} \sigma$-holes apply. In particular, i) the observation about the constantly negative source from the pyr ring and the always positive contribution from the $p y r^{\prime}$ ring, and ii) the large increase of the magnitude of the $\mathrm{SF}(p y r)$ on passing from $\mathrm{Ch}=\mathrm{S}$ to $\mathrm{Ch}=\mathrm{Se}$, yet to values $(-0.039 /-0.532)$ which are almost twice as big as for the $C_{\text {pyridyl }}-\mathrm{Ch} \sigma$-holes. It is thus once more evident that the contribution of the Bipy moiety is the result of quite distinct sources from its two composing ring moieties. As anticipated, sources from the $3^{\prime}-\mathrm{H}$ and the $5^{\prime}-\mathrm{Br}$ atoms to the $\mathrm{C}_{\mathrm{R}}-\mathrm{Ch}$ $\sigma$-holes potential maxima are significantly affected in their magnitudes by molecular conformation.

In particular, $\mathrm{SF}\left(5^{\prime}-\mathrm{Br}\right)$ is quite high in magnitude and negative for $\mathrm{A} 1(-0.009 /-0.017 \mathrm{au})$ and $\mathrm{B} 1$ conformers $\left(-0.017 /-0.020 \mathrm{au}\right.$; the higher magnitude value is reported for cases with two $\mathrm{C}_{\mathrm{R}}-\mathrm{Ch}$ $\sigma$-holes maxima), while it is marginally negative or even positive for other conformers (A2 and B2). To be facing (A1 and B1) or not facing (A2 and B2) the $\sigma$-hole, drastically changes the role the $5^{\prime}$-Br atom plays in determining the corresponding $V_{\mathrm{S}, \max }$ value. The source from $3^{\prime}-\mathrm{H}$ is invariably positive and large $(0.010 / 0.026 \mathrm{au})$, but particularly large for those conformers where $\mathrm{SF}\left(5^{\prime}-\mathrm{Br}\right)$ is almost negligible. For instance, $\mathrm{SF}\left(3^{\prime}-\mathrm{H}\right)$ is as large as $0.025 / 0.026$ au for the $\mathrm{B} 2$ conformers.

\subsubsection{Aryl $\pi$-Holes}

Decomposing $\pi$-hole potentials into $\mathrm{Ch}, \mathrm{R}$ and Bipy SF contributions (Table S5) neatly highlights the reasons leading, for $\mathrm{R}=\mathrm{Ph}$, to negative and small in magnitude $V_{\mathrm{S} \text {, max }}$ values and, for $\mathrm{R}=\mathrm{C}_{6} \mathrm{~F}_{5}$, to large and positive $V_{\mathrm{S} \text {, max }}$ values, regardless of $\mathrm{Ch}$ being $\mathrm{S}$ or $\mathrm{Se}$. When $\mathrm{R}=\mathrm{Ph}$ (compounds 2 
and 5), the negative $\mathrm{SF}(\mathrm{R})$ contribution is roughly of the same order of magnitude as the positive $\mathrm{SF}(\mathrm{Ch})$ contribution and the two sources almost cancel each other. As a result, $V_{\mathrm{S} \text {, max }}$ turns out to be mostly determined by the negative and small SF(Bipy) contribution. Conversely, when $R=\mathrm{C}_{6} \mathrm{~F}_{5}$ (compounds 3 and 6), $\mathrm{SF}(\mathrm{R})$ becomes much smaller in magnitude than $\mathrm{SF}(\mathrm{Ch})$. In fact, the former source drastically decreases its magnitude relative to that observed for compounds 2 and 5 , while the latter source slightly increases its positive value relative to these compounds because $\mathrm{C}_{6} \mathrm{~F}_{5}$ withdraws more electrons from the $\mathrm{Ch}$ atom than the $\mathrm{Ph}$ group does. Combined with the fact that also SF(Bipy) of $\mathbf{3}$ and $\mathbf{6}$ becomes smaller in magnitude than for compounds $\mathbf{2}$ and $\mathbf{5}$ and definitely smaller than $\mathrm{SF}(\mathrm{Ch})$, the largely positive $\mathrm{SF}(\mathrm{Ch})$ source provides about $90 \%$ of the $V_{\mathrm{S}, \max }$ value for conformers 3 or even overdetermines largely $(140-190 \%)$ this value for conformers 6 . The fact that for conformers 6 $\mathrm{SF}$ (Bipy) is (much) less negative than for compounds $\mathbf{2}$ and $\mathbf{5}$ or that it becomes close to zero, or even positive for conformers 3 , is easily explained. Indeed, the strong electron-withdrawing power of $\mathrm{C}_{6} \mathrm{~F}_{5}$ dampens the electron flow from the $\mathrm{Ch}$ atom to the Bipy moiety making this moiety less negatively charged and with a correspondingly (much) less negative source, relative to the case of $\mathrm{R}=\mathrm{Ph}$ [for instance, for A1 conformers, the Bipy net charge decreases in magnitude from -0.121 to $-0.060 \mathrm{e}^{-}(2 \rightarrow 3)$ and from -0.227 to $-0.159 \mathrm{e}^{-}(\mathbf{5} \rightarrow \mathbf{6})$ ]. Dissection of SF(Bipy) in its two ring components $\mathrm{SF}(p y r)$ and $\mathrm{SF}\left(p_{\left.y r^{\prime}\right)}\right)$ shows that the former is negative, as its six-membered-ring (6MR) carries the Ch substitution, and, except for 3-A1, always prevails in magnitude, while the latter is always positive. The $\mathrm{SF}(\mathrm{Ph})$ for the $\pi$-hole potentials is always negative, because the negative contribution from the $6 \mathrm{MR} C$ atoms overweighs the positive SF contribution from their linked $\mathrm{H}$ atoms. On the other hand, for $\mathrm{R}=\mathrm{C}_{6} \mathrm{~F}_{5}$ the $6 \mathrm{MR} C$ atoms significantly increase their positive charge because of the $\mathrm{H} \rightarrow \mathrm{F}$ substitution and so provide an overall positive source contribution at the $\pi$-holes. When $\mathrm{Ch}=\mathrm{S}$, the negative $\mathrm{SF}$ contribution from the fluorine atoms prevails over the positive contribution from the $6 \mathrm{MR}$, while just the opposite occurs when Se replaces $S$, because the $C$ atoms become even more positively charged and their positive SF contribution significantly increases.

External and internal $\pi$-hole potentials exhibit qualitatively the same SF contribution trends as a function of the $\mathrm{R}$ and $\mathrm{Ch}$ nature. There is, however, an important exception for conformers 2-A2 and 5-A2, whose internal $\pi$-holes exhibit significantly more negative $V_{\mathrm{S}, \max }$ values $(-0.0138$ and $-0.0160 \mathrm{au})$ than those of their external $\pi$-holes $(-0.0090$ and $-0.0081 \mathrm{au})$. Please note that the potential values for the internal $\pi$-holes are the more negative ones for the whole set of investigated systems. The apparent anomaly (illustrated in Figure 6 for the 5-A2 $\pi$-holes) finds an easy explanation in terms of $\mathrm{SF}\left(5^{\prime}-\mathrm{Br}\right)$ values and considering that in the 2-A2 and 5-A2 conformers the $5^{\prime}$ - $\mathrm{Br}$ atom points its $\pi$-cloud towards the phenyl ring internal $\pi$-hole. Indeed, the $\mathrm{SF}\left(5^{\prime}-\mathrm{Br}\right)$ value is always negative for these conformers but as small as -0.0023 and -0.0025 au for the external and about 6 times as large $(-0.0153$ and $-0.0173 \mathrm{au})$ for the internal 2-A2 and 5-A2 $\pi$-holes. Such an increase in magnitude qualitatively explains the potential differences between the external and internal $\pi$-holes for these two conformers.

\subsection{Analysis of $V_{S, \max }$ and Source Function (SF) Contributions Changes}

Further precious insights on the trends of the $V_{S, \max }$ values and their atomic (group) sources may be gained by decomposing the changes in their values upon chemical substitution into chemically meaningful contributions. Table $\mathrm{S} 6$ (Supplementary Information) displays $V_{\mathrm{S}, \max }$ variations $\left(\Delta V_{\mathrm{S}, \max }\right)$ and corresponding SF contributions changes $(\triangle \mathrm{SF})$ upon substitution of either $\mathrm{Ch}$ or $\mathrm{R}$ atom/group or of both of them for a given conformer of systems 1-6. $\Delta V_{\mathrm{S}, \max }$ values and their composing $\Delta \mathrm{SF}$ contributions for a system change $\mathrm{X} \rightarrow \mathrm{Y}$ are evaluated as $\Delta \mathrm{Z}=\mathrm{Z}(\mathrm{Y})-\mathrm{Z}(\mathrm{X})$ where $\mathrm{Z}=V_{\mathrm{S} \text {, } \max }$ or $\mathrm{SF}$. Conformers were kept fixed for any considered $X \rightarrow Y$ change avoiding to introduce a further (and possibly second-order) variable in the analysis. The $\Delta V_{\mathrm{S}, \max }$ values may be decomposed as

$$
\Delta V_{\mathrm{S}, \max }(\mathrm{X} \rightarrow \mathrm{Y}) \cong \mathrm{SF}(\mathrm{Ch})+\Delta \mathrm{SF}(\mathrm{R})+\Delta \mathrm{SF}(\text { Bipy })
$$

where the "" sign in Equation (2) accounts for the unavoidable numerical integration error in the $\Delta \mathrm{SF}$ reconstruction of the $\Delta V_{\mathrm{S}, \max }$ value. In Table S6, those $\Delta \mathrm{SF}$ and $\Delta \mathrm{SF} \%$ values that refer to $\mathrm{Ch}$ and 
$R$ moieties undergoing a substitutional change upon the $X \rightarrow Y$ change of system are shown in bold. Equation (2) may also be recast as Equation (3):

$$
\Delta V_{\mathrm{S}, \max }(\mathrm{X} \rightarrow \mathrm{Y}) \cong \mathrm{SF}_{\text {substitution }}+\Delta \mathrm{SF}_{\text {rearrangement }}
$$

where the $\Delta \mathrm{SF}_{\text {substitution }}$ term includes all the sources of groups undergoing a change of chemical composition (shown in bold in Table S6) while the $\Delta \mathrm{SF}_{\text {rearrangement }}$ term is the sum of $\Delta \mathrm{SF}$ (Bipy) and of those $\Delta \mathrm{SF}(\mathrm{Ch})$ or $\Delta \mathrm{SF}(\mathrm{R})$ contributions arising from the $\mathrm{Ch}$ and $\mathrm{R}$ moieties that are not substituted in the $\mathrm{X} \rightarrow \mathrm{Y}$ process (all sources yielding as a sum $\Delta \mathrm{SF}_{\text {rearrangement }}$ are shown not in bold in Table $\mathrm{S6}$ ). For the sake of clarity, Figure 7 (left plot) illustrates the $\Delta$ SF decompositions given by Equations (2) and (3) in an exemplar case.

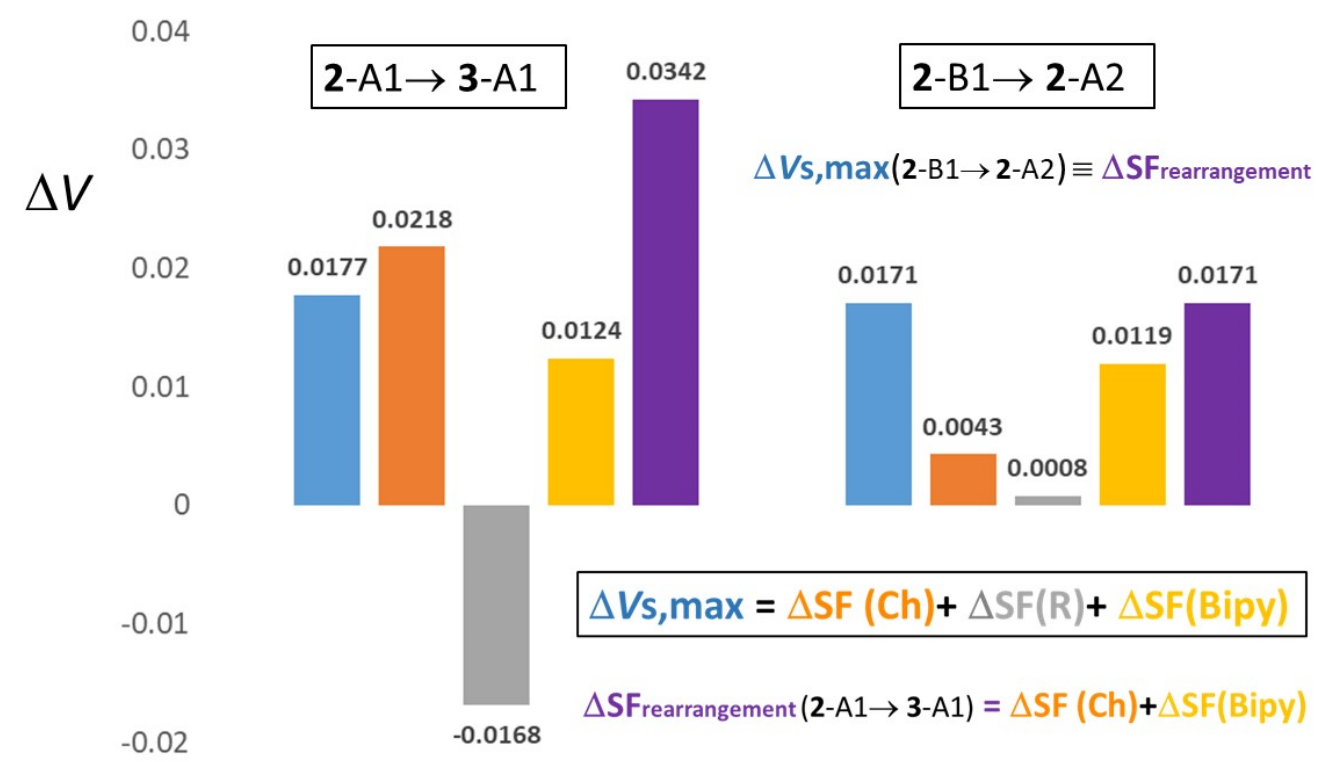

Figure 7. $\Delta V_{\mathrm{S}, \max }(\mathrm{X} \rightarrow \mathrm{Y})(\mathrm{au})$ Source Function (SF) decomposition in two exemplar cases (see Tables $\mathrm{S6}$ and $\mathrm{S} 7$ for the full list of cases and $\Delta \mathrm{SF}$ decomposition data). Data refer to the $\mathrm{C}_{\mathrm{R}}-\mathrm{S} \sigma$-holes $\Delta V_{\mathrm{S} \text {, max }}$ changes for a case (2-A1 $\rightarrow 3$ - $\mathrm{A} 1)$ where the system undergoes chemical substitution $\left(\mathrm{Ph} \rightarrow \mathrm{C}_{6} \mathrm{~F}_{5}\right)$ and no conformational change and for a case $(2-\mathrm{B} 1 \rightarrow \mathbf{2}-\mathrm{A} 2)$ where only conformational change occurs. The two considered molecular transformations yield quite similar $V_{S, \max }$ variations, yet the roles of the $\mathrm{Ch}, \mathrm{R}$, and Bipy moieties in producing such similar changes strikingly differ. In particular, it is shown that a change of molecular conformation only may be as effective as a chemical substitution in its impact on the $V_{\mathrm{S}, \max }$ value. The different magnitude and composition of the $\Delta \mathrm{SF}_{\text {rearrangement }}$ term in the two cases is shown, while $\Delta \mathrm{SF}_{\text {substitution }}$ equals $\Delta \mathrm{SF}(\mathrm{Ch})$ for the 2 - $\mathrm{A} 1 \rightarrow 3-\mathrm{A} 1$ case and it is identically equal to zero for the 2 -B1 $\rightarrow 2-\mathrm{A} 2$ case.

Both $\Delta \mathrm{SF}_{\text {substitution }}$ and $\Delta \mathrm{SF}_{\text {rearrangement }}$ may be large and often (much) larger in magnitude than the $\Delta V_{\mathrm{S}, \max }$ value they reconstruct (Table S6). When larger in magnitude than $\Delta V_{\mathrm{S} \text {, max }}$, these two additive terms need to oppose each other to yield the observed $\Delta V_{\mathrm{S} \text {, max }}$ value (within the SF reconstruction error). Thus, a chemical moiety substitution quite often induces a substantial charge rearrangement also in those moieties whose chemical formula remains fixed. Such a moiety rearrangement is mirrored in its SF contribution change following the $X \rightarrow Y$ process. Said in other words, each $\Delta V_{\mathrm{S}, \max }$ value for a system change $X \rightarrow Y$ results from both the substituted and the only apparently untouched moieties. For the sake of conciseness, the analysis worked out in Table $\mathrm{S} 6$ refers only to the $\mathrm{C}_{\text {pyridyl }}-\mathrm{Ch}$ and the $\mathrm{C}_{\mathrm{R}}-\mathrm{Ch} \sigma$-holes.

\subsubsection{S $\rightarrow$ Se Substitutions}

Looking at Table $\mathrm{S} 6$ in more detail, one observes that when $\mathrm{R}$ is fixed, $\triangle \mathrm{SF}(\mathrm{Ch})$ for the $\mathrm{C}_{\text {pyridyl }}-\mathrm{Ch}$ $\sigma$-holes remains positive and almost constant $(0.0552 / 0.0582 \mathrm{au})$ for all $\mathrm{S} \rightarrow$ Se changes, while a 
larger spread $(0.0324 / 0.0744 \mathrm{au})$ is observed for the $\mathrm{C}_{\mathrm{R}}-\mathrm{Ch}$ holes. A similar behavior is found for $\Delta \mathrm{SF}(\mathrm{R})$ and $\triangle \mathrm{SF}$ (Bipy) which are however negative and thus opposing rather than contributing to the positive $\Delta V_{\mathrm{S}, \max }$ values. In particular, $\Delta \mathrm{SF}(\mathrm{R})$ and $\Delta \mathrm{SF}$ (Bipy) amount to $-0.0281 /-0.0325$ au and $-0.0163 /-0.0186 \mathrm{au}$, respectively, for the $C_{\text {pyridyl }}-C$ Ch $\sigma$-holes and to $-0.0164 /-0.0177$ au and $-0.0124 /-0.0462 \mathrm{au}$, respectively, for the $C_{R}-C h$ holes. Since $\Delta S F(C h)$ values are all largely positive and fairly exceeding the corresponding $\Delta V_{\mathrm{S} \text {, max }}$ values, $\Delta \mathrm{SF}_{\text {rearrangement }}$ turns out to be also largely negative, almost constant for $\mathrm{C}_{\text {pyridyl }}-\mathrm{Ch}$ holes $(-0.0453 /-0.0514 \mathrm{au})$ and significantly more spread out $(-0.0291 /-0.0629 \mathrm{au})$ for the $\mathrm{C}_{\mathrm{R}}-\mathrm{Ch}$ holes.

\subsection{2. $\mathrm{R} \rightarrow \mathrm{R}^{\prime}$ Substitutions}

At variance with the case of fixed $\mathrm{R}$ and $\mathrm{S} \rightarrow$ Se substitution, keeping the $\mathrm{Ch}$ fixed and changing $\mathrm{R}$ to $R^{\prime}$ leads to more complex variations. On passing from $R=$ Me to $R^{\prime}=P h$ or $R^{\prime}=C_{6} F_{5}$ or from $R=P h$ to $R^{\prime}=C_{6} F_{5}, \Delta S F\left(R \rightarrow R^{\prime}\right)$ is always negative. It is also largely spread out $(-0.0069 /-0.0371 \mathrm{au})$ and in all cases, save two from $\mathrm{R}=$ Me to $\mathrm{R}^{\prime}=\mathrm{Ph}\left(\mathbf{1}\right.$-A1 $\rightarrow$ 2-A1 and 1-A2 $\rightarrow$ 2-A2, $\mathrm{C}_{\text {pyridyl }}-\mathrm{Ch} \sigma$-holes), significantly opposing the potential change $\Delta V_{\mathrm{S}, \max }$. Conversely, $\Delta \mathrm{SF}$ (Bipy) is always positive and largely varying $(0.0033 / 0.0266 \mathrm{au}) . \Delta \mathrm{SF}(\mathrm{Ch})$ is also usually positive and quite large $(0.0104 / 0.0315 \mathrm{au})$, despite being only due to charge density rearrangements within the $\mathrm{S}$ or Se atomic basins (plus changes due to variations in the $\sigma$-holes maxima locations). In three specific cases, however, $\triangle \mathrm{SF}(\mathrm{Ch})$ is negligibly small (1-A1 $\rightarrow 2$-A1; 1-A2 $\rightarrow$ 2-A2; $\mathrm{C}_{\text {pyridyl }}-\mathrm{Ch} \sigma$-holes) or even negative (2-B1 $\rightarrow 3-\mathrm{B} 1, \mathrm{C}_{\mathrm{R}}-\mathrm{Ch}$ lower magnitude $\sigma$-hole). $\Delta \mathrm{SF}_{\text {rearrangement }}$ is always positive, generally quite large $(0.0144-0.0430 \mathrm{au})$ and significantly overdetermining the potential change, except for the two cases where $\Delta V_{\mathrm{S} \text {, max }}$ is negative rather than positive. In such an event $\left(\mathbf{1}-\mathrm{A} 1 \rightarrow \mathbf{2}\right.$-A1; 1 -A2 $\rightarrow \mathbf{2}$ - $\mathrm{A} 2 ; \mathrm{C}_{\text {pyridyl }}-\mathrm{Ch} \sigma$-holes) $\Delta \mathrm{SF}_{\text {rearrangement }}$ is quite small (about $0.0050 \mathrm{au}$ ) and counteracts the potential change.

\subsection{3. $\mathrm{S} \rightarrow \mathrm{Se}$ and $\mathrm{R} \rightarrow \mathrm{R}^{\prime}$ Substitutions}

The double substitution case is also complex to analyze, being the result of the rearrangement of the electron distribution of the Bipy moiety and of the $\mathrm{Ch}$ and $\mathrm{R}$ group replacements. However, two clear indications may be deduced from Table S6. First, $\triangle \mathrm{SF}$ (Bipy) that in such case equals $\Delta \mathrm{SF}_{\text {rearrangement }}$ by definition, is always negative and large or moderately large in magnitude. It also opposes the potential change except in one single case (1-A1 $\rightarrow 5$-A $1, \mathrm{C}_{\text {pyridyl }}-\mathrm{Ch} \sigma$-hole) where $\Delta V_{\mathrm{S} \text {,max }}$ is also negative. Secondly, $\Delta \mathrm{SF}(\mathrm{Ch})$ is invariably positive, quite large $(0.0324-0.0886 \mathrm{au})$ and significantly overdetermining $\Delta V_{\mathrm{S}, \max }$, except the single case where the latter is negative. $\Delta \mathrm{SF}(\mathrm{R})$ is instead always negative and smaller in magnitude than $\triangle \mathrm{SF}(\mathrm{Ch})$.

\subsubsection{Conformational Changes}

Table S7 (Supplementary information) details the last step of our $\Delta V_{\mathrm{S}, \max }$ analysis. Differently from Table S6, where the $\Delta \mathrm{SF}$ changes due to $\mathrm{R}$ and/or $\mathrm{Ch}$ replacement have been discussed keeping the same conformation type, data in Table S7 refer to the supposedly less perturbing case of a conformation change only. In this instance, we would expect (significantly) lower $\Delta \mathrm{SF}$ values. Moreover, being by assumption $\Delta \mathrm{SF}_{\text {substitution }}$ equal to zero, $\Delta V_{\mathrm{S}, \max }(\mathrm{X} \rightarrow \mathrm{Y}) \cong \Delta \mathrm{SF}_{\text {rearrangement }}$ (Equation (3)).

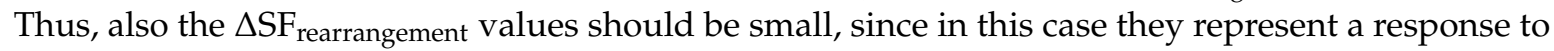
only a conformational change, rather than to a substitutional change in another moiety of the molecule. For the sake of simplicity, Table S7 lists data related to the Ch $\sigma$-holes only. The $\Delta V_{\mathrm{S} \text {, max }}$ values for the $\mathrm{C}_{\text {pyridyl }}-\mathrm{Ch} \sigma$-holes are indeed small and arising, in general, from somewhat higher in magnitude $\Delta \mathrm{SF}(\mathrm{W} ; \mathrm{W}=\mathrm{Ch}, \mathrm{R}, \mathrm{Bipy})$ values since the $\mathrm{Ch}, \mathrm{R}$, and Bipy source differences do not have all the same sign. In practice, they may individually concur to or oppose the observed $\Delta V_{\mathrm{S}, \max }$ value. The potential difference values for the $C_{R}-C h \sigma$-holes are instead quite large in many cases. The composing source differences $\Delta \mathrm{SF}(\mathrm{W})$ show different behaviors among themselves and an exemplar case is shown in Figure 7 (right plot). $\Delta \mathrm{SF}(\mathrm{R})$ is generally quite small, analogously to the case of the $\mathrm{C}_{\text {pyridyl }}-\mathrm{Ch}$ holes. Thus, the $\Delta S F(R)$ values do not appreciably contribute to the $\sigma$-hole potential changes due to the 
conformational changes. Conversely, $\triangle \mathrm{SF}(\mathrm{Ch})$ and $\Delta \mathrm{SF}(\mathrm{Bipy})$ are in most cases quite large and may both concur or may, either one or the other, oppose to the observed $\Delta V_{\mathrm{S} \text {, max }}$ values, according to the investigated conformational change. In summary, the quite large $\Delta V_{\mathrm{S} \text {,max }}$ values for $\mathrm{C}_{\mathrm{R}}-\mathrm{Ch} \sigma$-holes are in many cases the result of even larger changes in the source contributions of the $\mathrm{Ch}$ and the Bipy moieties. These results show the noteworthy importance of the $\Delta \mathrm{SF}_{\text {rearrangement }}$ contributions in determining hole potential changes, even when arising from the sole molecular conformational change. Indeed, the $\Delta \mathrm{SF}_{\text {rearrangement }}(\mathrm{W})$ value include two contributing factors, one due to the change of the electron distribution within the $\mathrm{W}$ moiety and the other due to the changes in the $1 /\left|r-r^{\prime}\right|$ electron density weighting function. According to the location of the potential hole and the nature of the conformational change, the second geometrical factor may acquire a great relevance, while the former factor is generally much less important for a conformational change only. This is indeed the case for the $\Delta \mathrm{SF}\left(\mathrm{W}=\mathrm{Ch}\right.$, Bipy) values of $\mathrm{C}_{\mathrm{R}}-\mathrm{Ch} \sigma$-holes, where large displacements $(>0.2 \mathrm{au})$ of the holes from the Ch nucleus are observed upon many of the conformational changes listed in Table S7 (Supplementary Information).

\section{Materials and Methods}

The 3D structures of the configurational $M$ isomers of compounds 1-6 were prepared using the build function, and model kits and tools provided by Spartan' 10 Version 1.1.0 (Wavefunction Inc., Irvine, CA, USA) [48] for building and editing organic molecules. On this basis, molecules were generated, and their structure refinement was performed by a MMFF (Molecular Mechanics Force Field) procedure. Then, each structure was submitted to a conformational systematic search using the MMFF, spanning all shapes accessible to the molecule irrespective of their relative energies. After the elimination of duplicates and high-energy conformers, a set of energetically accessible conformers was selected. For each conformer, geometry optimization in vacuum was performed employing the density functional theory (DFT) method with the B3LYP functional and the 6-311G* basis set (available for elements $\mathrm{H}-\mathrm{Ca}, \mathrm{Ga}-\mathrm{Kr}$, and I). Computation of $V_{\mathrm{S}}$ values, given in au (electrons/bohr), was performed by using Gaussian 09 (Wallingford, CT, USA) and at DFT/B3LYP/6-311G* level [49]. Search for the exact location of $V_{\mathrm{S}, \max }$ was made through the Multiwfn code [50] and through its module enabling quantitative analyses of $V_{\mathrm{S}}$ on molecular electron density isosurfaces (isovalue $0.002 \mathrm{au}$ ) [51]. $V_{\mathrm{S}}$ representations of all conformers of 1-6 depicted in the text (Figure 2 and Supplementary Information) were graphically generated by using Spartan' 10 through its graphic interface. For the SF reconstruction of $V_{\mathrm{S}, \max }$ values, a small code, VEXTLOC [52], was written to associate $V_{\mathrm{S}, \max }$ to the various atomic basins and to select those maxima of interest for the $V_{\mathrm{S}} \mathrm{SF}$ analysis. Atomic association was made based on the distance between each $V_{\mathrm{S}}$ extremum and each atomic nucleus in the system. Our standard SF code [53] SF_ESI, was then generalized to include the case of $V_{\mathrm{S}}$ SF reconstruction in terms of Quantum Theory of Atoms in Molecules (QTAIM) [54] basin contributions, so that both fields, electron density (ED) and $V_{\mathrm{S}}$ may be simultaneously reconstructed at the same set of reference points (rps) [55]. Such $V_{\mathrm{S}}$ SF reconstruction is quantitatively analogous to evaluating $V_{\mathrm{S}}$ as a sum of the electrostatic potential contribution of all QTAIM atomic basins of a molecule [56]. The SF_ESI code was also used to evaluate the net charges (nuclear charge minus electron population) of QTAIM atomic basins. The SF_ESI code reads wavefunction information from the .wfn files, produced as output by several ab initio packages. In our computations .wfn files were obtained through the Gaussian09 package [49]. Another small code, ANASFR_EP (Analyse SF Results for $V_{\mathrm{S}}$ field), was written to extract $V_{\mathrm{S}}$ atomic SF data calculated by the generalized SF code and to suitably combine them to get $V_{S}$ SF contributions from all atomic groups defined in input [57].

\section{Conclusions}

This study focused on the interplay between halogen and chalcogen $\sigma$-holes, and aromatic $\pi$-holes located in the same class of molecules as chemical and conformational variations occur. For this purpose, conformers of six 5,5'-dibromo-2,2' -dichloro-3-chalcogen-4,4'-bipyridines were used as test 
probes, and $V_{\mathrm{S} \text {, max }}$ values of eight holes carried by the heteroaromatic scaffold were calculated and compared in order to evaluate the impact of chemical and conformational variations on the hole depth. With the aim to gain further insights on the contribution of atoms or groups of the molecule to generate certain $V_{\mathrm{S} \text {, max }}$ values, the Bader-Gatti SF for the electron density was extended to the electrostatic potential. Naively, a hole $V_{\mathrm{S} \text {, } \max }$ is thought to increase as the remainder of the molecule becomes more electron-attracting. However, $V_{\mathrm{S}, \max }$ analysis and reconstruction showed that the $V_{\mathrm{S} \text {,max }}$ values associated with $\sigma$ - and $\pi$-holes located in complex molecular systems depend on the subtle balance of several effects which contribute to increase or decrease the potential value associated with the electron charge density depletion. In particular, negative or positive $V$ contribution from neighboring portions of the molecule were found to significantly concur in determining $V_{S \text {, max }}$ along with electronegativity and polarizability properties of bound atoms and groups. The results of this study serve the molecular design of $\mathrm{XB}, \mathrm{ChB}$, and $\pi$-hole bond donors for applicative purposes, clarifying how chemical and conformational features impact hole regions and affect their potential involvement in noncovalent interactions.

Supplementary Materials: The following are available online. Table S1: Energies and structural properties of low energy optimized (B3LYP/6-311G*) conformers of compounds 1-6, Figure S1: $V_{\mathrm{S}}$ representations on electron density isosurfaces $(0.002 \mathrm{au})$ for conformers of compounds 2, 3, and 5, Figure S2: Se $\cdots \mathrm{N}$ ChB in crystal packing of conformer 5-B2 (CCDC no. 1963860), Table S2: $V_{\mathrm{S}, \max }$ calculated for conformer 6-B1 with different method/basis set, Figure S3: Linear correlation between $\sigma$ - and $\pi$-holes calculated with different methods/basis set, Table S3: Energies and structural properties of low energy optimized B3LYP/6-311G* conformers of compound 7, Table S4: $V_{\mathrm{S}, \max }$ on halogen $(\mathrm{Cl}, \mathrm{Br})$ and $\pi$-holes calculated for conformers 7-A1, 7-A2, 7-B1, and 7-B2, Table S5: $V_{\mathrm{S} \text {, max }}$ and their Source Function (SF) atomic group contributions on external and internal $\pi$-holes calculated for the various conformers of systems 2-3 and 5-6, Table S6: $V_{\mathrm{S}, \max }$ variations $\left(\Delta V_{\mathrm{S}, \max }\right)$ of $\mathrm{C}_{\text {pyridyl }}-\mathrm{Ch}$ and $\mathrm{C}_{\mathrm{R}}-\mathrm{Ch}(\mathrm{Ch}=\mathrm{S}$, Se) $\sigma$-holes and corresponding Source Function (SF) contributions changes $(\triangle \mathrm{SF})$ upon substitution of $C h$ or $R$ atom/group or of both of them for a given conformer of systems 1-6, Table $\mathrm{S} 7: \Delta V_{\mathrm{S} \text {,max }}$ and their $\Delta \mathrm{SF}$ atomic group contributions on $C_{\text {pyridyl }}-\mathrm{Ch}$ and on $\mathrm{C}_{\mathrm{R}}-\mathrm{Ch} \sigma$-holes calculated upon change of conformation for systems 1-6.

Author Contributions: Conceptualization, C.G., P.P. (Paol. Peluso) and V.M.; methodology, P.P. (Paol Peluso) and C.G.; syntheses, V.M., P.P. (Patrick Pale) and R.W.; X-ray analysis, E.A.; $V_{\text {s }}$ calculations, P.P. (Paol Peluso), A.D. and R.D.; SF reconstruction, C.G.; writing-original draft preparation, P.P. (Paol Peluso) and C.G.; writing, review, and editing, all authors; funding acquisition, V.M., S.C., and C.G. All authors have read and agreed to the published version of the manuscript.

Funding: This research was funded by Venice Ca' Foscari University, Italy (Department of Molecular Science and Nanosystems, DSMN ADIR funds), the International Center Frontier Research in Chemistry (icFRC), the LabEx CSC (ANR-10-LABX-0026 CSC), and Danmarks Grundforskningsfond (award No. DNRF93).

Acknowledgments: This work has been supported by Università Ca' Foscari Venezia, Italy (Dipartimento di Scienze Molecolari e Nanosistemi DSMN, ADIR funds) and International Center Frontier Research in Chemistry (icFRC), the LabEx CSC (ANR-10-LABX-0026 CSC). C.G. acknowledges funding from Danmarks Grundforskningsfond (award No. DNRF93).

Conflicts of Interest: The authors declare no conflict of interest.

\section{References}

1. Scrocco, E.; Tomasi, J. The electrostatic molecular as a tool for the interpretation of molecular properties. Top. Curr. Chem. 1973, 42, 95-170. [CrossRef]

2. Clark, T. Halogen bonds and $\sigma$-holes. Faraday Discuss. 2017, 203, 9-27. [CrossRef] [PubMed]

3. Murray, J.S.; Politzer, P. Molecular electrostatic potentials and noncovalent interactions. WIREs Comput. Mol. Sci. 2017, 7, e1326. [CrossRef]

4. Brinck, T.; Murray, J.S.; Politzer, P. Surface electrostatic potentials of halogenated methanes as indicators of directional intermolecular interactions. Int. J. Quantum Chem. 1992, 44, 57-64. [CrossRef]

5. Clark, T.; Hennemann, M.; Murray, J.S.; Politzer, P. Halogen bonding: The o-hole. J. Mol. Model. 2007, 13, $291-296$. [CrossRef] [PubMed]

6. Politzer, P.; Murray, J.S.; Clark, T. Halogen bonding and other $\sigma$-hole interactions: A perspective. Phys. Chem. Chem. Phys. 2013, 15, 11178-11189. [CrossRef]

7. Politzer, P.; Murray, J.S. An overview of strengths and directionalities of noncovalent interactions: $\sigma$-hole and $\pi$-holes. Crystals 2019, 9, 165. [CrossRef] 
8. Desiraju, G.R.; Shing Ho, P.; Kloo, L.; Legon, A.C.; Marquardt, R.; Metrangolo, P.; Politzer, P.; Resnati, G.; Rissanen, K. Definition of the halogen bond (IUPAC Recommendations 2013. Pure Appl. Chem. 2013, 85, 1711-1713. [CrossRef]

9. Aakeroy, C.B.; Bryce, D.L.; Desiraju, G.R.; Frontera, A.; Legon, A.C.; Nicotra, F.; Rissanen, K.; Scheiner, S.; Terraneo, G.; Metrangolo, P.; et al. Definition of the chalcogen bond (IUPAC Recommendations 2019). Pure Appl. Chem. 2019, 91, 1889-1892. [CrossRef]

10. Cavallo, G.; Metrangolo, P.; Milani, R.; Pilati, T.; Priimagi, A.; Resnati, G.; Terraneo, G. The halogen bond. Chem. Rev. 2016, 116, 2478-2601. [CrossRef]

11. Mahmudov, K.T.; Kopylovich, M.N.; Guedes da Silva, M.F.C.; Pombeiro, A.J.L. Chalcogen bonding in synthesis, catalysis and design of materials. Dalton Trans. 2017, 46, 10121-10138. [CrossRef] [PubMed]

12. Vogel, L.; Wonner, P.; Huber, S.M. Chalcogen bonding: An overview. Angew. Chem. Int. Ed. 2019, 58, $1880-1891$. [CrossRef] [PubMed]

13. Biot, N.; Bonifazi, D. Chalcogen-bond driven molecular recognition at work. Coord. Chem. Rev. 2020, 413, 213243. [CrossRef]

14. Murray, J.S.; Macaveiu, L.; Politzer, P. Factor affecting the strengths of $\sigma$-hole electrostatic potentials. J. Comput. Sci. 2014, 5, 590-596. [CrossRef]

15. Wheeler, S.E.; Houk, K.N. Through-space effects of substituents dominate molecular electrostatic potentials of substituted arenes. J. Chem. Theory Comput. 2009, 5, 2301-2312. [CrossRef] [PubMed]

16. Bundhun, A.; Ramasami, P.; Murray, J.S.; Politzer, P. Trends in $\sigma$-hole strengths and interactions of $F_{3} M X$ molecules (M = C, Si, Ge and X = F., Cl, Br, I). J. Mol. Mod. 2013, 19, 2739-2746. [CrossRef] [PubMed]

17. Riley, K.E.; Tran, K.-A.; Lane, P.; Murray, J.S.; Politzer, P. Comparative analysis of electrostatic potential maxima and minima on molecular surface, as determined by three methods and a variety of basis sets. J. Comput. Sci. 2016, 17, 273-284. [CrossRef]

18. Kolář, M.H.; Hobza, P. Computer modeling of halogen bonds and other $\sigma$-hole interactions. Chem. Rev. 2016, 116, 5155-5187. [CrossRef]

19. Aakeröy, C.B.; Chopade, P.D.; Desper, J. Establishing a hierarchy of halogen bonding by engineering crystals without disorder. Cryst. Growth Des. 2013, 13, 4145-4150. [CrossRef]

20. Aakeröy, C.B.; Wijethunga, T.K.; Desper, J.; Đaković, M. Electrostatic potential differences and halogen-bond selectivity. Cryst. Growth Des. 2016, 16, 2662-2670. [CrossRef]

21. Lange, A.; Heidrich, J.; Zimmermann, M.O.; Exner, T.E.; Boeckler, F.M. Scaffold effects on halogen bonding strength. J. Chem. Inf. Model. 2019, 59, 885-894. [CrossRef] [PubMed]

22. Dessì, A.; Peluso, P.; Dallocchio, R.; Weiss, R.; Andreotti, G.; Allocca, M.; Aubert, E.; Pale, P.; Mamane, V.; Cossu, S. Rational design, synthesis, characterization and evaluation of $4,4^{\prime}$-bipyridines as new transthyretin fibrillogenesis inhibitors. Molecules 2020, 25, 2213. [CrossRef]

23. Lim, J.Y.C.; Marques, I.; Thompson, A.L.; Christensen, K.E.; Félix, V.; Beer, P.D. Chalcogen bonding macrocycles and [2] rotaxanes for anion recognition. J. Am. Chem. Soc. 2017, 139, 3122-3133. [CrossRef] [PubMed]

24. Ams, M.R.; Trapp, N.; Schwab, A.; Milić, J.V.; Diederich, F. Chalcogen bonding "2S-2N squares" versus competing interactions: Exploring the recognition properties of sulfur. Chem. Eur. J. 2019, 25, 323-333. [CrossRef] [PubMed]

25. Nayak, S.K.; Kumar, V.; Murray, J.S.; Politzer, P.; Terraneo, G.; Pilati, T.; Metrangolo, P.; Resnati, G. Fluorination promotes chalcogen bonding in crystalline solids. CrystEngComm 2017, 19, 4955-4959. [CrossRef]

26. Politzer, P.; Murray, J.S. $\sigma$-holes and $\pi$-holes: Similarities and differences. J. Comput. Chem. 2018, 39, 464-471. [CrossRef]

27. Bauzá, A.; Frontera, A.; Mooibroek, T.J. $\pi$-Hole interactions involving nitro aromatic ligands in protein structures. Chem. Eur. J. 2019, 25, 13436-13443. [CrossRef]

28. Abboud, M.; Mamane, V.; Aubert, E.; Lecomte, C.; Fort, Y. Synthesis of polyhalogenated 4, 4'-bipyridines via a simple dimerization procedure. J. Org. Chem. 2010, 75, 3224-3231. [CrossRef]

29. Mamane, V.; Peluso, P.; Aubert, E.; Cossu, S.; Pale, P. Chiral hexahalogenated 4, 4'-bipyridines. J. Org. Chem. 2016, 81, 4576-4587. [CrossRef]

30. Peluso, P.; Mamane, V.; Aubert, E.; Dessì, A.; Dallocchio, R.; Dore, A.; Pale, P.; Cossu, S. Insights into halogen bond-driven enantioseparations. J. Chromatogr. A 2016, 1467, 228-238. [CrossRef]

31. Peluso, P.; Mamane, V.; Dallocchio, R.; Dessì, A.; Villano, R.; Sanna, D.; Aubert, E.; Pale, P.; Cossu, S. Polysaccharide-based chiral stationary phases as halogen bond acceptors: A novel strategy for detection of stereoselective $\sigma$-hole bonds in solution. J. Sep. Sci. 2018, 41, 1247-1256. [CrossRef] [PubMed] 
32. Peluso, P.; Gatti, C.; Dessì, A.; Dallocchio, R.; Weiss, R.; Aubert, E.; Pale, P.; Cossu, S.; Mamane, V. Enantioseparation of fluorinated 3-arylthio-4, 4'-bipyridines: Insights into chalcogen and $\pi$-hole bonds in high-performance liquid chromatography. J. Chromatogr. A 2018, 1567, 119-129. [CrossRef] [PubMed]

33. Weiss, R.; Aubert, E.; Peluso, P.; Cossu, S.; Pale, P.; Mamane, V. Chiral chalcogen bond donors based on the 4, 4'-bipyridine scaffold. Molecules 2019, 24, 4484. [CrossRef] [PubMed]

34. Benz, S.; López-Andarias, J.; Mareda, J.; Sakai, N.; Matile, S. Catalysis with chalcogen bonds. Angew. Chem. Int. Ed. 2017, 56, 812-815. [CrossRef]

35. O'Hair, R.A.J.; Williams, C.M.; Clark, T. Neighboring group stabilization by $\sigma$-holes. J. Mol. Model. 2010, 16, 559-565. [CrossRef]

36. Riel, A.M.S.; Huynh, H.-T.; Jeannin, O.; Berryman, O.; Fourmigué, M. Organic selenocyanates as halide receptors: From chelation to one-dimensional systems. Cryst. Growth Des. 2019, 19, 1418-1425. [CrossRef]

37. Trujillo, C.; Rozas, I.; Elguero, J.; Alkorta, I.; Sánchez-Sanz, G. Modulating intramolecular chalcogen bonds in aromatic (thio)(seleno) phene-based derivatives. Phys. Chem. Chem. Phys. 2019, 21, 23645-23650. [CrossRef]

38. Lu, T.; Zheng, Y.; Gou, Q.; Hou, G.-L.; Feng, G. Rotational characterization of S... F chalcogen bonds in the complex of 2, 2, 4, 4-tetrafluoro-1, 3-dithietane and difluoromethane. Phys. Chem. Chem. Phys. 2019, 21, 24659-24665. [CrossRef]

39. Bader, R.F.W.; Gatti, C. A Green's function for the density. Chem. Phys. Lett. 1998, 287, 233-238. [CrossRef]

40. Gatti, C.; Cargnoni, F.; Bertini, L. Chemical information from the source function. J. Comput. Chem. 2003, 24, 422-436. [CrossRef]

41. Gatti, C. The source function descriptor as a tool to extract chemical information from theoretical and experimental electron densities. Struct. Bond. 2012, 147, 193-286. [CrossRef]

42. Varadwaj, A.; Marques, H.M.; Varadwaj, P.R. Is the fluorine in molecules dispersive? Is molecular electrostatic potential a valid property to explore fluorine-centered non-covalent interactions? Molecules 2019, 24, 379. [CrossRef] [PubMed]

43. Bauzá, A.; Frontera, A. On the importance of halogen-halogen interactions in the solid state of fullerene halides: A combined theoretical and crystallographic study. Crystals 2017, 7, 191. [CrossRef]

44. Bader, R.F.W.; Carroll, M.T.; Cheeseman, J.R.; Chang, C. Properties of atoms in molecules: Atomic volumes. J. Am. Chem. Soc. 1987, 109, 7968-7979. [CrossRef]

45. Allred, A.L. Electronegativity values from thermochemical data. Inorg. Nucl. Chem. 1961, 17, 215-221. [CrossRef]

46. Lide, D.R. Handbook of Chemistry and Physics, 87th ed.; Taylor \& Francis: Boca Raton, FL, USA, 2006.

47. Kirshenboim, O.; Kozuch, S. How to twist, split and warp a $\sigma$-hole with hypervalent halogens. J. Phys. Chem. A 2016, 120, 9431-9445. [CrossRef]

48. Shao, Y.; Molnar, L.F.; Jung, Y.; Kussmann, J.; Ochsenfeld, C.; Brown, S.T.; Gilbert, A.T.B.; Slipchenko, L.V.; Levchenko, S.V.; O'Neil, D.P.; et al. Advances in methods and algorithms in a modern quantum chemistry program package. Phys. Chem. Chem. Phys. 2006, 8, 3172-3191. [CrossRef]

49. Frisch, M.J.; Trucks, G.W.; Schlegel, H.B.; Scuseria, G.E.; Robb, M.A.; Cheeseman, J.R.; Scalmani, G.; Barone, V.; Mennucci, B.; Petersson, G.A.; et al. Gaussian 09, Revision, B. 01; Gaussian, Inc.: Wallingford, CT, USA, 2010.

50. Lu, T.; Chen, F. Multiwfn: A multifunctional wavefunction analyser. J. Comp. Chem. 2012, 33, 580-592. [CrossRef]

51. Lu, T.; Chen, F. Quantitative analysis of molecular surface based on improved marching tetrahedra algorithm. J. Mol. Graph. Model. 2012, 38, 314-323. [CrossRef]

52. Gatti, C. VEXTLOC Code; CNR-ISTM: Milano, Italy, 2018.

53. Gatti, C. SF-ESI Codes; CNR-ISTM: Milano, Italy, 2015.

54. Bader, R.F.W. Atoms in Molecules: A Quantum Theory, International Series of Monographs on Chemistry 22; Oxford University Press: Oxford, UK, 1990.

55. Gatti, C. SF_ED_EP_ESI Codes; CNR-ISTM: Milano, Italy, 2018.

56. Kosov, D.S.; Popelier, P.L.A. Atomic Partitioning of Molecular Electrostatic Potentials. J. Phys. Chem. A 2000, 104, 7339-7345. [CrossRef]

57. Gatti, C. ANASFR_EP Code; CNR-ISTM: Milano, Italy, 2018.

(C) 2020 by the authors. Licensee MDPI, Basel, Switzerland. This article is an open access article distributed under the terms and conditions of the Creative Commons Attribution (CC BY) license (http://creativecommons.org/licenses/by/4.0/). 